\title{
Air-Sea Coupled Data Assimilation Experiment for Typhoons Kilo, Etau and the September 2015 Kanto-Tohoku Heavy Rainfall with the Advanced Microwave Scanning Radiometer 2 Sea Surface Temperature
}

\author{
Akiyoshi WADA \\ Typhoon Research Department, Meteorological Research Institute, Tsukuba, Japan \\ Hiroshige TSUGUTI \\ Forecast Research Department, Meteorological Research Institute, Tsukuba, Japan \\ Kozo OKAMOTO \\ Typhoon Research Department, Meteorological Research Institute, Tsukuba, Japan \\ and \\ Naoko SEINO \\ Forecast Research Department, Meteorological Research Institute, Tsukuba, Japan
}

(Manuscript received 8 March 2018, in final form 27 December 2018)

\begin{abstract}
The September 2015 Kanto-Tohoku heavy rainfall event occurred in a stationary linear convective system between Typhoons Kilo and Etau. We investigated the influence of sea surface temperature (SST) on the local heavy rainfall event using a regional air-sea strongly coupled data assimilation system based on the local ensemble transform Kalman filter (LETKF) and a nonhydrostatic atmosphere model (NHM) coupled with an oceansurface wave model and a multilayer ocean model with an Advanced Microwave Scanning Radiometer 2 (AMSR2) level 2 (L2) SST product. From the validation of SST analyzed by the coupled data assimilation system with the Japanese geostationary multi-functional transport satellite 2 hourly SST product and in-situ observations at a moored buoy, we demonstrated that the coupled system with the AMSR2 L2 SST led to an improvement in the SST analysis. Based on the verification using radiosonde observations and radar-rain gauge rainfall analysis, the analysis of the lower-atmospheric components was improved by the air-sea coupled NHM-LETKF.

The local torrential rainfall event that occurred around $37^{\circ} \mathrm{N}$ in the Tochigi prefecture was embedded in a stationary linear convective system. The location of the linear convective system corresponded to the synoptic-scale convergence area between the cyclonic circulation associated with Etau and easterly lower-tropospheric winds. Strong southerly winds associated with Etau caused a periodic enhancement of local convection along the convergence area on the upwind side of the linear convective system and resulted in a wave-like train of the total water content around an altitude of $4-8 \mathrm{~km}$ on the leeward side. The improvement of SST analysis could not only change the transition of Etau to the extratropical cyclone but also the lower-tropospheric wind field and thereby
\end{abstract}

Corresponding author: Akiyoshi Wada, Meteorological Research Institute, 1-1, Nagamine, Tsukuba, Ibaraki 305-0052, Japan

E-mail: awada@mri-jma.go.jp

J-stage Advance Published Date: 19 January 2019

(CThe Author(s) 2019. This is an open access article published by the Meteorological Society of Japan under a Creative Commons Attribution 4.0 International (CC BY 4.0) license (https://creativecommons.org/licenses/by/4.0). 
the location of the stationary linear convective system with embedded local torrential rain.

Keywords air-sea coupled data assimilation; sea surface temperature; linear convective system; typhoon

Citation Wada, A., H. Tsuguti, K. Okamoto, and N. Seino, 2019: Air-sea coupled data assimilation experiment for Typhoons Kilo, Etau and the September 2015 Kanto-Tohoku Heavy Rainfall with the Advanced Microwave Scanning Radiometer 2 sea surface temperature. J. Meteor. Soc. Japan, 97, 553-575, doi:10.2151/jmsj.2019-029.

\section{Introduction}

A current numerical weather forecasting system is constructed based on atmospheric observation data, an atmospheric data assimilation system, and an atmospheric numerical model. The state-of-the-art numerical weather forecasting system is a mission-critical system and needs to be improved continuously to prevent natural disasters and to mitigate the damage that they cause. Advancements in the supercomputer system enable the numerical model to have higher resolution and to be more sophisticated with the advancement of observational technology and a variety of observation data (Brunet et al. 2010; Bauer et al. 2015). In particular, with the progress of satellite technology, various satellites such as geostationary/polar orbiters have been launched. Since the observation area is spatially and temporally limited, however, incorporating the data appropriately into the atmospheric analysis is important to the improvement of weather forecasts. The Global Change Observation MissionWater "Shizuku" (GCOM-W) satellite equipped with the Advanced Microwave Scanning Radiometer-2 (AMSR2) microwave radiometer (e.g., Tomita et al. 2015) is one of the progressive microwave satellites with multi-frequency channels. The satellite can observe the amounts of precipitation, water vapor, sea surface temperature (SST), and near surface wind speed over the global ocean.

An analysis field of SST, which is required as the lower boundary condition of the atmosphere model, has been conventionally created by an ocean data assimilation system (e.g., Kurihara et al. 2006) and is not directly linked with an atmosphere data assimilation system (e.g., Kunii 2014). For this reason, the atmospheric field analyzed by the atmosphere data assimilation system is not always consistent with the oceanic field analyzed by the ocean data assimilation system. Lea et al. (2015) studied air-sea weakly coupled data assimilation, which used forecasts calculated by an atmosphere-ocean coupled model to provide the background field, while analysis of the atmosphere and ocean was updated in each assimilation system. Since atmospheric physical components interact with SST, an air-sea strongly coupled assimilation system which takes the covariance between the atmosphere and the ocean into account is expected to be a nextgeneration numerical weather forecasting system (Brunet et al. 2010). In an air-sea strongly coupled system, observational information is shared between the atmosphere and ocean models (Liu et al. 2013; Sluka et al. 2016; Smith et al. 2015, 2017).

Previous studies have investigated the role of ocean coupling in the atmospheric analysis using the atmospheric data assimilation system based on the local ensemble transform Kalman filter (LETKF) (Miyoshi and Kunii 2012; Kunii and Miyoshi 2012) and the data assimilation system of which forecast portion was a nonhydrostatic atmospheric model (NHM) coupled with a 1-dimensional ocean model (Kunii et al. 2017). Here, we present the new development of a regional air-sea strongly coupled system based on NHMLETKF (Wada and Kunii 2017), although a control variable in the ocean portion of the system is limited to SST. Wada and Kunii (2017) constructed a regional air-sea strongly coupled data assimilation system for the first time and demonstrated the advantage of analyzing a tropical cyclone and an SST field as well as their predictions for Typhoon Sinlaku (2008).

One of the main challenges is to accurately predict extreme rainfall events with a longer lead time. Such events have a large and sometimes devastating effect on social communities, and those occurring in developed countries are no exception. According to a nationwide survey in the United States, two of the most important aspects of such prediction are when and where precipitation will occur (Lazo et al. 2009). This study focuses on the linear convective system in Japan that occurred along $140^{\circ} \mathrm{E}$ and did not change its location for about 36 hours in September 2015 (Fig. 1). Local torrential rain was continuously embedded inside the stationary linear convective system around $37^{\circ} \mathrm{N}$ in the Kanto region on $9-10$ September. The system moved eastward on 11 September, and the 

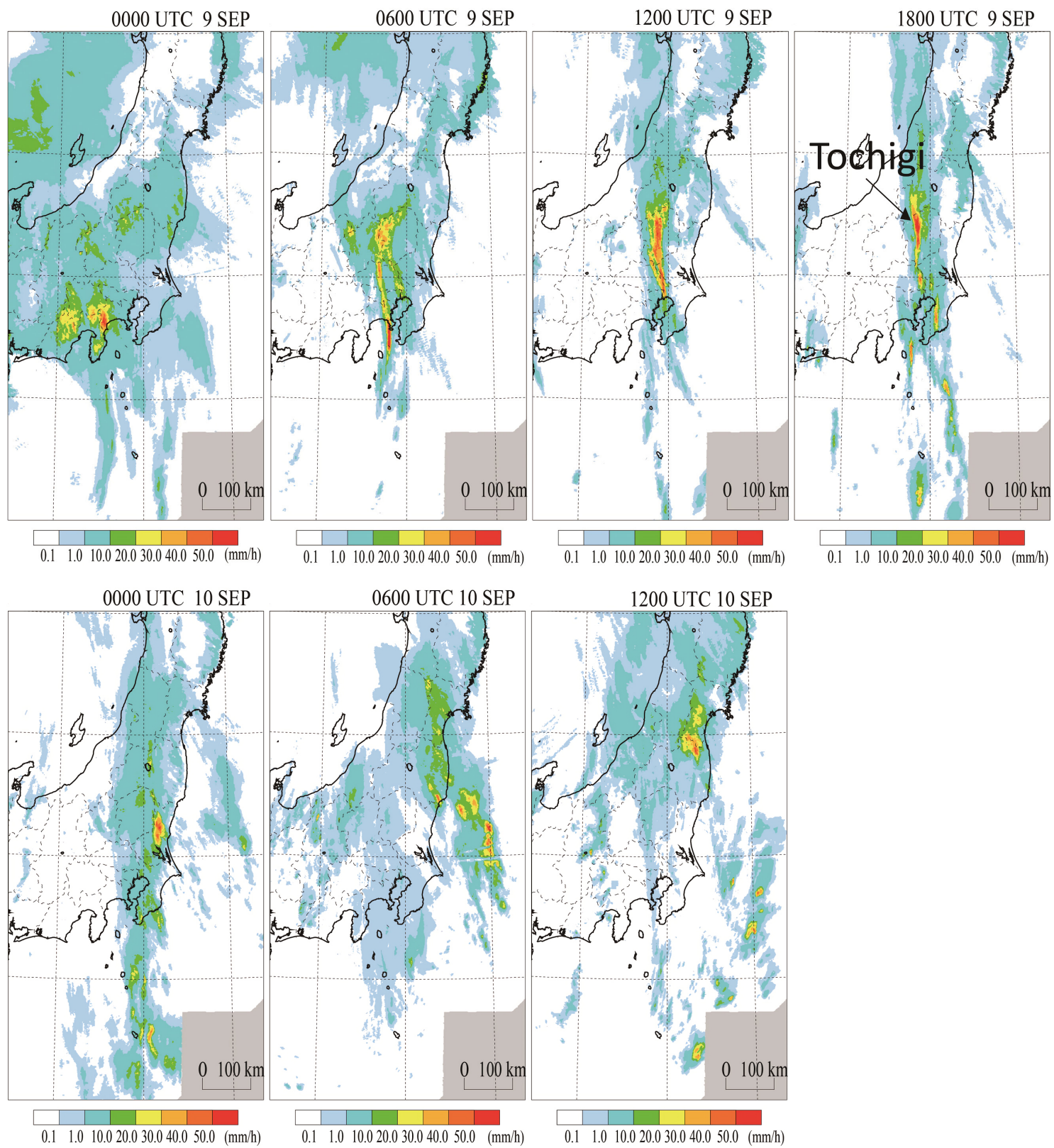

Fig. 1. Horizontal distribution of the radar-rain gauge analyzed hourly precipitation amount every six hours from 0000 UTC on 9 September to 1200 UTC on 10 September in 2015.

linear convective system then stagnated in the Tohoku area.

The synoptic structure surrounding the linear convective system was characterized by Typhoon Kilo (2015) and the extratropical cyclone associated with Typhoon Etau (2015) (Fig. 2). Regarding the analysis and predictability of stationary linear convective systems and local torrential rain, the possibility of improving the numerical forecast by assimilating Himawari-8 rapid-scan atmospheric motion vectors (Kunii et al. 2016) and using a sophisticated atmosphere data assimilation system (Lien et al. 2017; Honda et al. 2018) has been reported. Lien et al (2017) pointed out that a high-resolution atmospheric model with a horizontal resolution of a few kilometers is needed to improve the forecast. However, the effect 

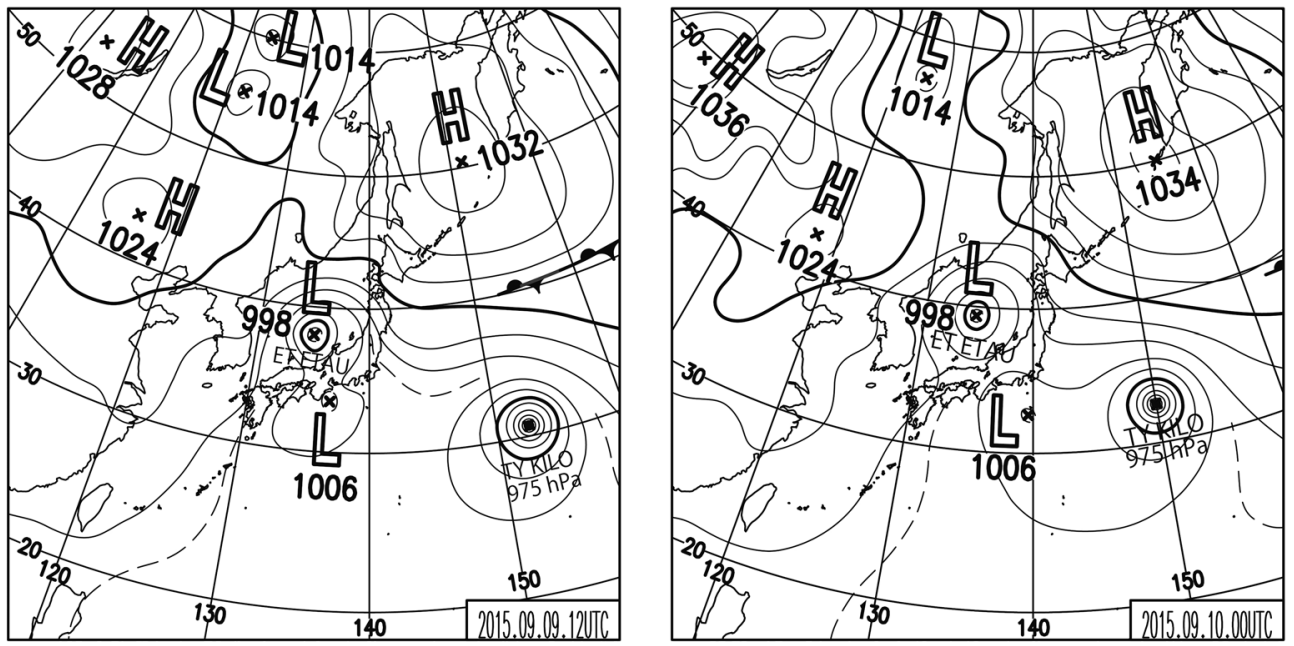

Fig. 2. Weather maps around Japan at 2100 UTC on 9 September (left panel) and at 0000 UTC on 10 September (right panel) in 2015.

of diabatic heating caused by changes in SST on the stationary linear convective system was not investigated in these studies, while previous studies pointed out the importance of SST (Tsuguti and Kato 2014a; Manda et al. 2014; Kunoki et al. 2015; Sato et al. 2016), lower-tropospheric moisture (Peters et al. 2017; Schumacher 2015; Schumacher and Peters 2017), and warm air advection (Peters and Schumacher 2015a, b) for such heavy rainfall events.

The purpose of this study was to demonstrate the effect of accurate SST analysis on the analysis of the September 2015 Kanto-Tohoku heavy rainfall event that occurred in a stationary linear convective system over the Japanese archipelago between Kilo and the extratropical cyclone transited from Etau, particularly focusing on the stationary linear convective system across the Tochigi prefecture. This study employed the air-sea strongly coupled data assimilation system developed by Wada and Kunii (2017) with the AMSR2 SST product. Also, our focus is the effect of SST on the linear convective system and how extremely heavy rainfall occurred at a specified local area in the Tochigi prefecture (Fig. 1). This is the first attempt to apply the air-sea strongly coupled data assimilation system to analyze a stationary linear convective system with embedded local torrential rain.

This paper consists of five sections. After the introduction, Section 2 subsequently describes the data and method used in this study. Sections 3.1 and 3.2 present the results of assimilation and validation of SST and atmospheric components, such as hourly rainfall, winds, temperature, and relative humidity. Sections 3.3 and 3.4 show the results of the analysis regarding the linear convective system that occurred over the Japanese archipelago between Kilo and the extratropical cyclone transited from Etau. Section 4 discusses the roles of SST and ocean coupling on the analysis of the linear convective system. Section 5 is devoted to concluding remarks.

\section{Data and method}

This section explains the data and method used in this study. The air-sea strongly coupled data assimilation system is briefly explained in the schematic diagram presented in Fig. 3. New developments are associated with the analysis portion, where satellite SST data can be incorporated into the assimilation system as one of the control variables, and in the forecast portion, where the coupled atmosphere-waveocean model (Wada et al. 2010, 2013) is used instead of the NHM (Kunii 2014). The coupled model can realistically simulate tropical cyclones as well as storm-induced sea surface cooling (Wada et al. 2014) and the leveling off of drag coefficients under high winds (Wada et al. 2013). The analysis system takes the background error covariance between atmospheric and oceanic components into account, which the basis for referring to it as the air-sea strongly coupled assimilation system (Liu et al. 2013; Sluka et al. 2016; Smith et al. 2015, 2017; Wada et al. 2017).

The Group for High Resolution Sea Surface Temperature (GHRSST) Project Data Processing 


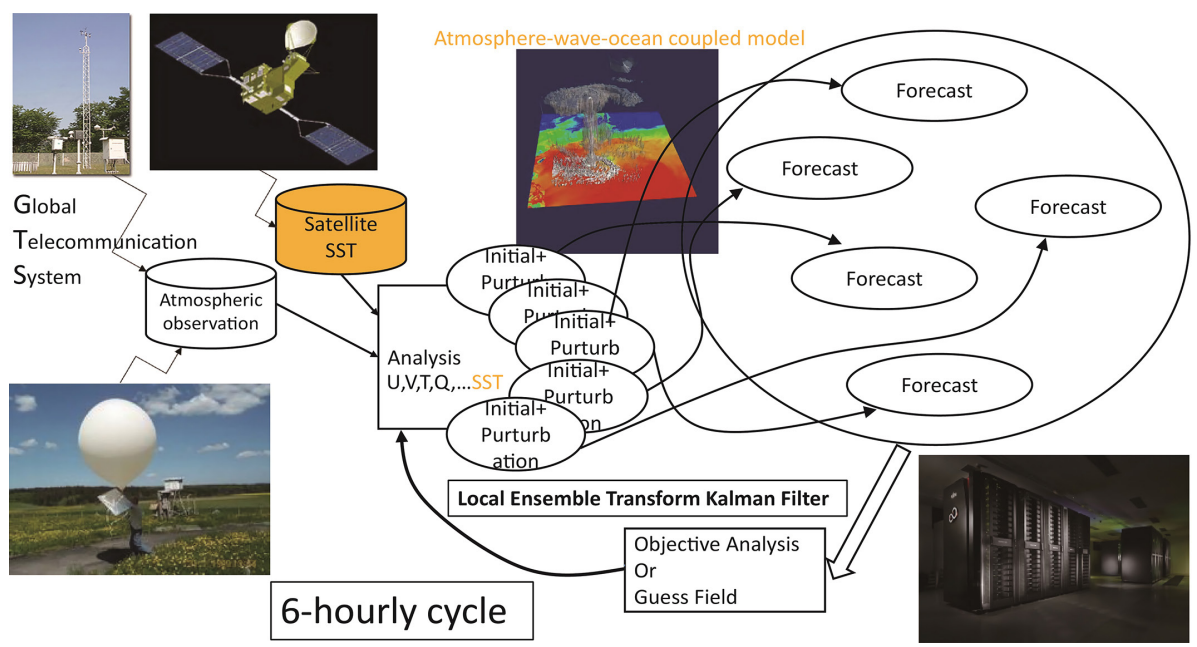

Fig. 3. Schematic diagram of a regional air-sea strongly coupled data assimilation system. The assimilation system enables to incorporate satellite SST data into the assimilation system as a control variable. The coupled atmosphere-wave-ocean model is used instead on the NHM in the forecast portion of the system.

Table 1. SST and ocean data used in this study.

\begin{tabular}{lccc}
\hline & Horizontal resolution & Temporal resolution & Area \\
\hline MGDSST & $0.25^{\circ}$ & daily & Global \\
AMSR2 L2P SST & $25 \mathrm{~km}$ & Scanning time & Global \\
MTSAT-2 SST & $4 \mathrm{~km}$ & hourly & Global \\
MOVE & $0.5^{\circ}$ & daily & North Pacific (Usui et al. 2006) \\
\hline
\end{tabular}

Specification version 2 format specifications (GDS2.0) version 2.1 Level 2P (L2P) Global Skin Sea Surface Temperature from AMSR2 on the GCOM-W satellite (http://suzaku.eorc.jaxa.jp/GHRSST/index.html) were used every hour within \pm 3 hours in each 6-hour cycle in conjunction with atmospheric observation data archived by the Japan Meteorological Agency (JMA). Hereafter, the SST is referred to as AMSR2 L2P SST. In addition, hourly SST retrieval derived from the Japanese geostationary and multi-functional transport satellite 2 (MTSAT-2) with a horizontal grid spacing of $0.04^{\circ}$ was used to validate the SST analyzed by the coupled system (Hereafter, it is called 'analyzed SST'). It should be noted that MTSAT-2 SST is independent of AMSR2 L2P SST, which makes it useful in validating the analysis. Table 1 shows a list of SST and ocean datasets used in this study.

The coupled data assimilation system covered an area of $4000 \mathrm{~km} \times 3300 \mathrm{~km}$ with the $273 \times 221$ grid points in the Lambert conformal projection. The configuration is the same as that in Kunii (2014). The horizontal grid spacing was $15 \mathrm{~km}$, and the number of vertical levels was 50, with different intervals ranging from $40 \mathrm{~m}$ for the near-surface layer to $1180 \mathrm{~m}$ for the uppermost layer. The top height was approximately $26 \mathrm{~km}$. The number of the ensemble members was 50 . To prevent an underestimation of ensemble spreads near lateral boundaries, lateral boundary uncertainties and uncertainties at the initial time were created from global objective analysis by adding perturbations derived from the JMA operational one-week ensemble prediction system. The variables controlled and analyzed in NHM-LETKF and the air-sea coupled system were three-dimensional wind components $(u, v, w)$, temperature $\left(T_{a}\right)$, pressure $(p)$, water vapor mixing ratio $\left(q_{v}\right)$, water/ice microphysics variables such as mixing ratio of cloud $\left(q_{c}\right)$, rain $\left(q_{r}\right)$, snow $\left(q_{s}\right)$, cloud ice $\left(q_{c i}\right)$, graupel $\left(q_{g}\right)$, and SST $\left(T_{s}\right)$. The covariance localization scales used in this study were set to 200 $\mathrm{km}$ in the horizontal direction, 0.2 in the vertical direction in the $\log p$ coordinate system, and a 3-hour time period. The localization parameters corresponded to the one-sigma length, where the Gaussian localization function became $e^{-0.5}$. These specifications are the 
same reported by Wada and Kunii (2017), except for the setting of the assimilation domain and the ensemble size.

The original NHM-LETKF experiment is referred to as 'CNTL' and the experiment with the air-sea strongly coupled data assimilation system (hereafter 'the coupled NHM-LETKF') together with AMSR2 L2P SST is referred to as 'CPL'.

The Merged Satellite and In-situ Data Global Daily Sea Surface Temperatures (MGDSST) dataset with a horizontal resolution of $0.25^{\circ}$ (Kurihara et al. 2006) was used as the SST boundary condition in the CNTL experiment. SST was fixed within four cycles in a day, which was the same as the configuration for SST in the original NHM system (Kunii 2014). It should be noted that AMSR2 L2P SST was used to create the MGDSST product after cutting the component to less than 27 days.

The initial oceanic conditions in the CPL experiment were created with the JMA objective analysis in 2015 and four-dimensional Variational Ocean ReAnalysis for the Western North Pacific over 30 years (FORA-WNP30) dataset (Usui et al. 2017: http:// synthesis.jamstec.go.jp/FORA/e/index.html) for the reference date (1 September) in different years and the associated data 5 days before the reference date (27 August) from 1990 to 2014 to create the initial perturbation ( 25 years $\times 2$ days $=50$ member) on the ocean side. The five days corresponded to the assimilation window for FORA-WNP30. The observation error of AMSR2 L2P SST was set at $3{ }^{\circ} \mathrm{C}$ based on the diurnal variation of SST (Kawai and Wada 2007). The assimilation window length of the coupled NHM-LETKF was 6 hours. Note that AMSR2 L2 SST data were directly assimilated without any bias corrections in the CPL experiment. Assimilated observation data included radiosonde, pilot balloon, wind profiler, aircraft, ship, buoy, total precipitable water obtained from the Global Navigation Satellite System, and atmospheric motion vectors derived from MTSAT-2. The relaxation-to-prior-spread method (Whitaker and Hamill 2012) was also adopted, and the relative weight of the background (analysis) was set to $0.95(0.05)$. The assimilation experiments started at 1200 UTC on 1 September and ended at 1800 UTC on 13 September in 2015.

\section{Results}

\subsection{SST analysis and validation}

Since the coupled NHM-LETKF is able to analyze SST every 6 hours, the analyzed SST field includes variations shorter than one day, the diurnal cycle of SST can be analyzed. In addition to the analysis of the diurnal cycle of SST, an overall improvement in the analyzed SST field is expected. Now, we focus on how the analyzed SST field was improved by the coupled NHM-LETKF with AMSR2 L2 SST (Fig. 4). The analyzed SST field at 1800 UTC on 9 September 2015 in the CPL experiment (Fig. 4b) was compared with the SST field at 1800 UTC on 9 September 2015 in the CNTL experiment (Fig. 4a) and the SST field derived from AMSR2 L2P SST (Fig. 4c) observed from 1500 UTC to 2100 UTC on 9 September 2015. The time 1800 UTC was selected because the SST field in the CNTL experiment was updated at 1800 UTC every four cycles.

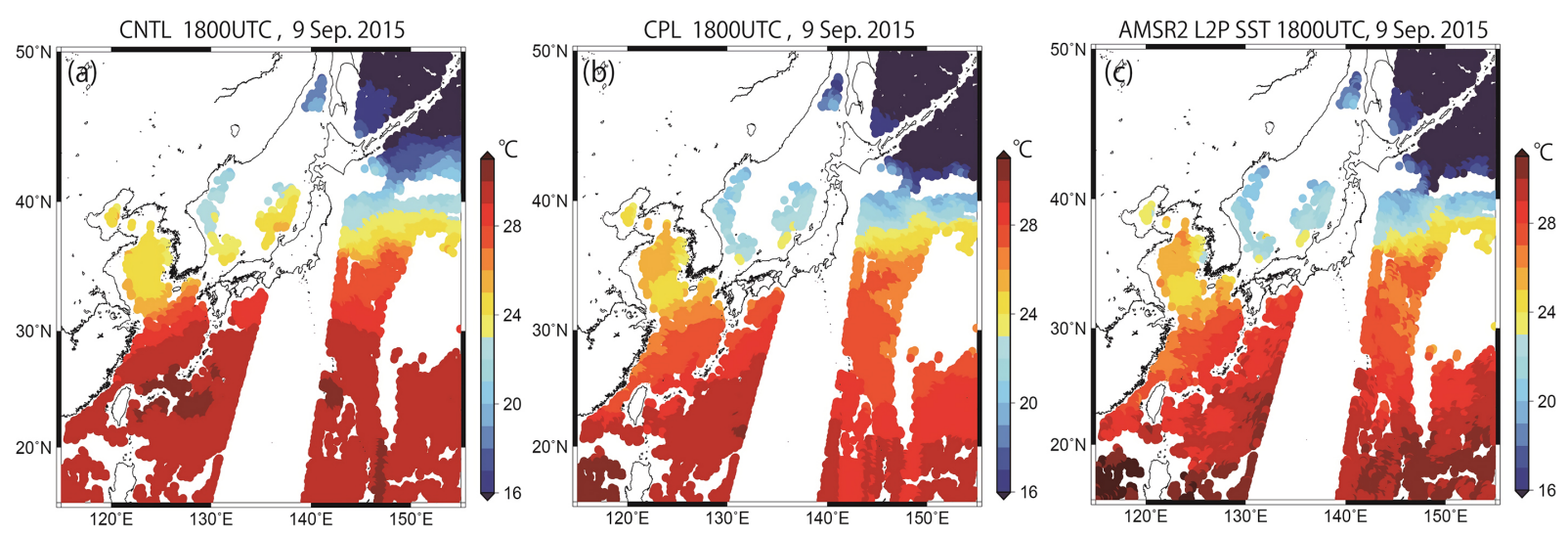

Fig. 4. Horizontal distributions of SST (a) used in the CNTL experiment, (b) analyzed by the air-sea coupled NHM-LETKF system in the CPL experiment, and (c) from AMSR2 L2P SST at 1800 UTC on 9 September 2015. AMSR2 L2P SST is depicted by data from 1500 UTC to 2100 UTC on 9 September 2015. 
Some areas in Fig. 4 where there is no AMSR2 L2 SST data were found due to thick clouds. The comparison revealed that the characteristics of AMSR2 L2P SST (Fig. 4c) was better analyzed in the CPL experiment (Fig. 4b) than in the CNTL experiment (Fig. 4a) in the following three points: [1] Around $25^{\circ} \mathrm{N}, 125^{\circ} \mathrm{E}$, SST in the CNTL experiment was $\sim 1^{\circ} \mathrm{C}$ higher than SST in the CPL experiment, [2] Around $30-35^{\circ} \mathrm{N}$, $145^{\circ} \mathrm{E}$, SST was relatively low in the CPL experiment due to strong surface winds associated with Kilo, and [3] Relatively high SST areas were found around the coastal area in the Sea of Japan in the CNTL experiment where the extratropical cyclone transited from Etau as it passed over.

Assimilated SST by the coupled NHM-LETKF was validated using in-situ SST observations at the Kuroshio Extension Observatory (KEO) buoy moored at $32.3^{\circ} \mathrm{N}, 144.6^{\circ} \mathrm{E}$. From the time series of SST at the grid corresponding to the location of the moored buoy, the diurnal variation in SST could be analyzed in the CPL experiment, while the diurnal variation could not be seen in the CNTL experiment (Fig. 5). The improvement of the diurnal SST variation amplitude led to an improvement of SST analyzed in the CPL experiment (Fig. 4b). Moreover, SST in the CNTL experiment had positive biases compared with SST analyzed in the CPL experiment and the in-situ SST observations at the moored buoy. The analyzed SST in the CPL experiment, however, had relatively small negative biases compared with in-situ SST observations even though AMSR2 L2 SST data were directly assimilated without any bias corrections.

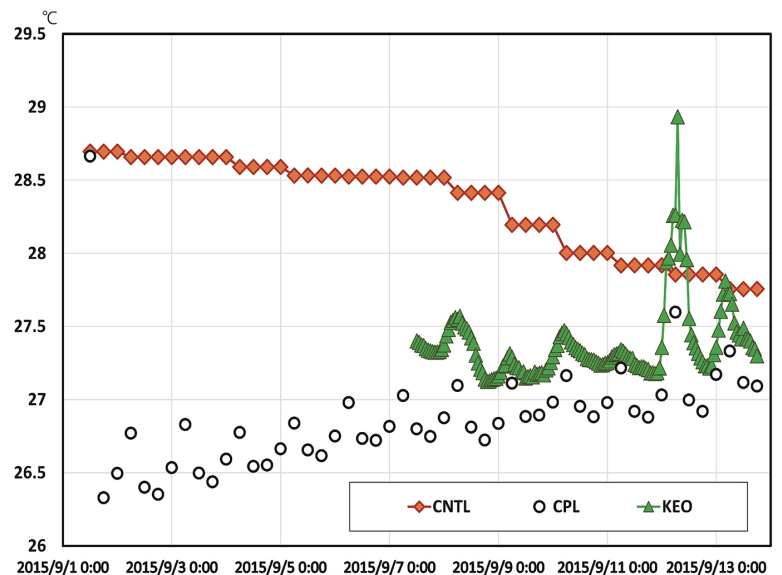

Fig. 5. Time series of in-situ observations and analyzed SST $\left({ }^{\circ} \mathrm{C}\right)$ at the location of the Kuroshio Extension Observatory moored buoy.
As described in Section 2, the MTSAT-2 SST was independent of AMSR2 L2 SST. This is the reason that MTSAT-2 SST was used to validate SST at 1800 UTC 9 September 2015 in the CNTL and CPL experiments (Fig. 6). SST in the CNTL experiment was relatively high compared with MTSAT-2 SST when SST was higher than $24^{\circ} \mathrm{C}$ (Fig. 6a). This is one of the causes of deterioration of the square of correlation coefficient $(0.54)$ and the slope $(0.67)$ of the linear

(a)

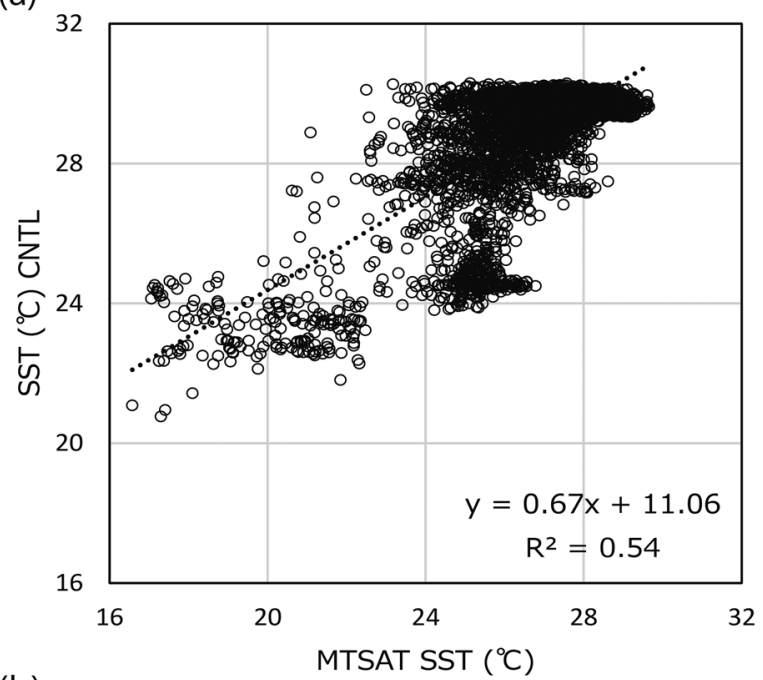

(b)

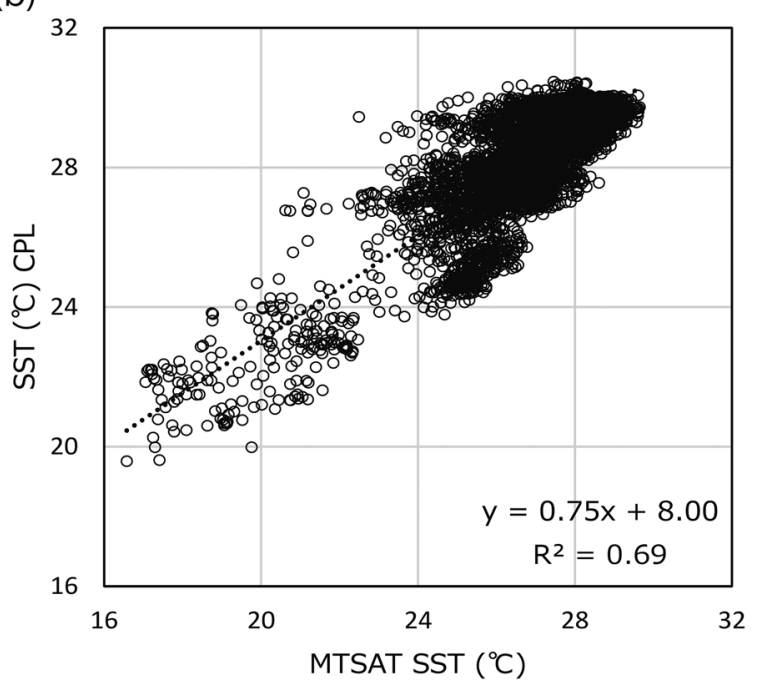

Fig. 6. Scatter diagrams on the relationship between MTSAT SST and (a) SST used in the CNTL experiment and (b) SST analyzed in the CPL experiment in a domain of $10-40^{\circ} \mathrm{N}$ and $115-145^{\circ} \mathrm{E}$ with the linear regression function and second power of correlation coefficient respectively. 
(a)

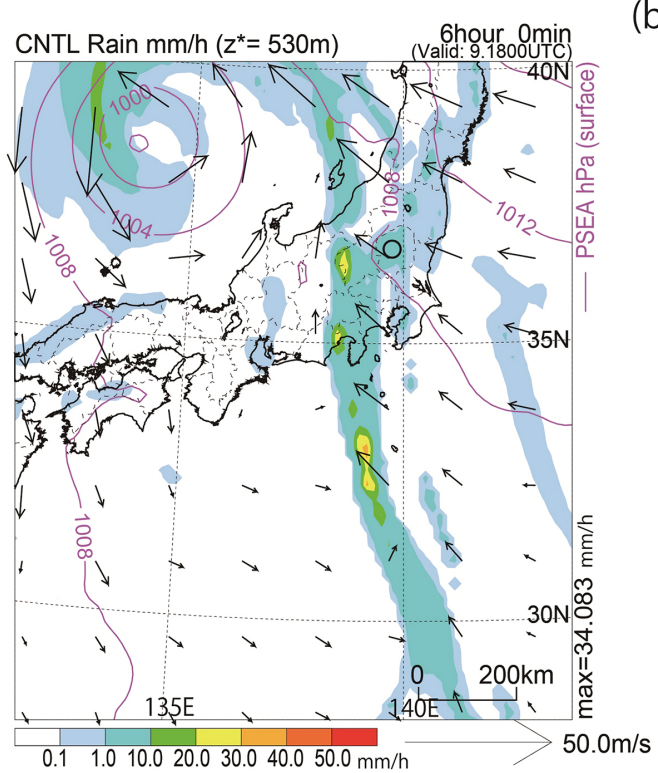

(b)

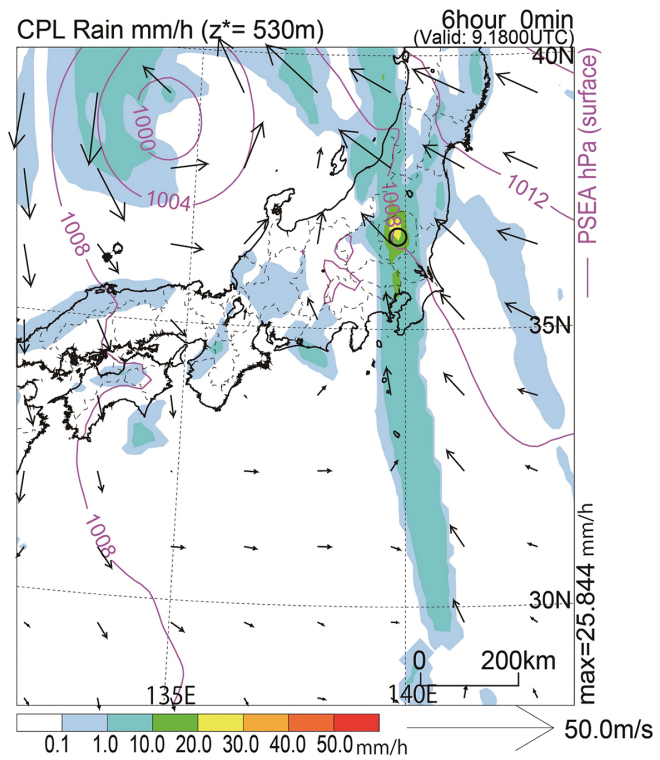

Fig. 7. Horizontal distributions of winds at a height of 530-m (vectors), sea level pressure (contours at the interval of $4 \mathrm{hPa}$ ), and hourly precipitation amount (colors) (a) analyzed in the CNTL experiment and (b) analyzed by the air-sea coupled NHM-LETKF system in the CPL experiment. Hourly precipitation amount is calculated from the total rainfall amount that occurred within an hour. An open black circle in each panel shows the location of the Tochigi prefecture.

regression function in the CNTL experiment. These values were improved in the CPL experiment (Fig. $6 \mathrm{~b})$. The square of correlation coefficient and slope increased to 0.69 and 0.75 , respectively. These results suggest that verification using hourly MTSAT-2 SST supported the improved quality of the analyzed SST in the CPL experiment.

\subsection{Analysis and validation of atmospheric components}

Hourly radar-rain gauge analyzed rainfall shown in Fig. 1 was estimated from the total rainfall amount within an hour based on radar observations calibrated with rain-gauge measurements from the JMA automated meteorological data acquisition system (Makihara 1996). Figure 1 captured the evolution of the stationary linear convective system and local torrential rain that occurred at the Kanto region. The precipitation pattern shown in Figs. $7 \mathrm{a}$ and $7 \mathrm{~b}$ was a result of 6-hour forecasts initiated at $1200 \mathrm{UTC}$ on 9 September in the CNTL (Fig. 7a) and CPL (Fig. $7 \mathrm{~b})$ experiments. Hereafter, the results of the forecast experiments initiated from the ensemble mean (see Fig. 1 in Miyoshi and Kunii 2012) were used for the analyses because the precipitation was a forecast variable both in the original and the coupled NHMLETKF. The orientation of the linear convective system in the CNTL experiment (Fig. 7a) was close to that in the radar-rain gauge analysis (Fig. 1). However, the location of the linear convective system over the Japanese archipelago in the CNTL experiment shifted westward compared with that shown in Fig. 1. The location of the linear convective system with embedded local torrential rain around $37^{\circ} \mathrm{N}$ in the Tochigi prefecture was successfully predicted in the CPL experiment (Fig. 7b).

Figure 8 shows the time series of total hourly rainfall from 0000 UTC on 9 September to 1800 UTC on 10 September in 2015 . The analyzed hourly radarrain gauge rainfall dataset used in this study was originally created with the method used in Tsuguti and Kato (2014a, b). The analysis area where the local torrential rain occurred was a rectangle surrounded by $36-37^{\circ} \mathrm{N}, 139-140^{\circ} \mathrm{E}$. The total hourly rainfall values over the area of $36-37^{\circ} \mathrm{N}, 139-140^{\circ} \mathrm{E}$ were calculated by summing hourly radar-rain gauge analyzed rainfall, hourly rainfall obtained in the CNTL experiment, and hourly rainfall obtained in the CPL experiment, respectively. At 1800 UTC on 9 September, the total hourly radar-rain gauge analyzed rainfall had a peak, 


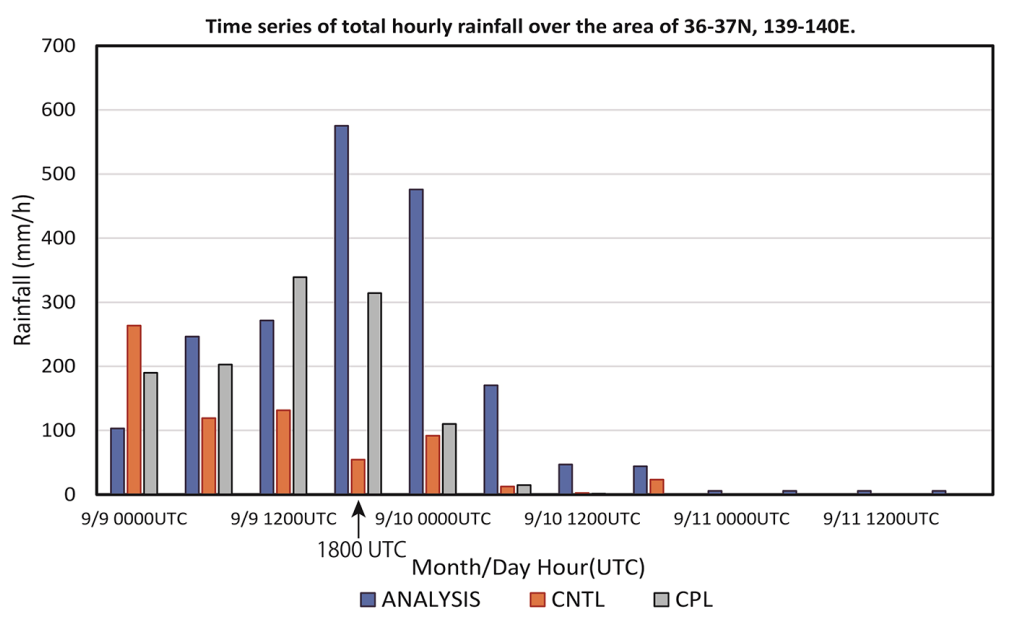

Fig. 8. Time series of the total amount of (a) hourly radar-rain gauge analyzed rainfall $\left(\mathrm{mm} \mathrm{h}^{-1}\right)$, (b) hourly rainfalls $\left(\mathrm{mm} \mathrm{h}^{-1}\right)$ obtained in the CNTL experiment and (c) hourly rainfalls $\left(\mathrm{mm} \mathrm{h}^{-1}\right)$ obtained in the CPL experiment over the area of $36-37^{\circ} \mathrm{N}, 139-140^{\circ} \mathrm{E}$ from $0000 \mathrm{UTC}$ in 9 September to 1800 UTC in 10 September in 2015 . The arrow indicates the time at 1800 UTC in 9 September in 2015.

while a peak of the total hourly rainfall was found at 1200 UTC on 9 September in the CPL experiment, six hours earlier than the occurrence of the peak of the total hourly radar-rain gauge analyzed rainfall. In the CNTL experiment, no peak was identified from 1200 UTC to 1800 UTC on 9 September in 2015.

Figure 9 shows scatter diagrams of hourly rainfall amounts between hourly radar-rain gauge analyzed rainfall and hourly rainfall in the CNTL (Fig. 9a)/CPL (Fig. 9b) experiment, respectively. It should be noted that the analysis area was different from that in Fig. 8 . The analysis area was a rectangle surrounded by $33-38^{\circ} \mathrm{N}, 138-141^{\circ} \mathrm{E}$, including the stationary linear convective system with embedded local torrential rain. Since the analysis area was expanded, the number of data samples increased, though only the result of the forecast initiated from the ensemble mean was used. There was no correlation between hourly radar-rain gauge analyzed rainfall and hourly rainfall in the CNTL experiment, while the correlation between radar-rain gauge analyzed rainfall and hourly rainfall in the CPL experiment was significant with a $p$-value much smaller than 0.05 . The result suggests that the improvement of the SST field analyzed by the coupled NHM-LETKF leads to the improvement of the hourly rainfall forecast.

Kunii et al. (2016) evaluated threat and bias scores for the 3-hourly accumulated precipitation averaged over eight different initial times. Following Kunii et al. (2016), we evaluated the mean thread score for a threshold of 3-hourly precipitation amounts from 0 to $20 \mathrm{~mm} \mathrm{~h}^{-1}$ averaged from 0000 UTC 9 to 1800 UTC 10 September 2015 every 6 hours (Fig. 10). The evaluated area was a relatively large rectangle surrounded by $28-42^{\circ} \mathrm{N}, 134-141^{\circ} \mathrm{E}$. Predictions of 3-hourly precipitation amount in the CPL experiment were improved at a threshold of over $5 \mathrm{~mm}$ compared with those in the CNTL experiment, although the threat score was degraded at the thresholds of 1 and 2 $\mathrm{mm}$, which is consistent with the result shown in Fig. 7. It should be noted that mean bias score in the CPL experiment was not improved (not shown) probably due to insufficient horizontal resolution $(15 \mathrm{~km})$ in both NHM-LETKF and the coupled NHM-LETKF even though SST analysis was improved in the CPL analysis. In fact, Wada et al. (2017) conducted forecast experiments on the September 2015 Kanto-Tohoku heavy rainfall event with a $3-\mathrm{km}$ mesh atmosphereocean coupled model that showed the hourly accumulated rainfall was quantitatively simulated to some extent.

The results of the analyses in the CNTL and CPL experiments were also verified with radiosonde observations during the period from 0000 UTC on 8 to 1800 UTC 13 September. The physical components were zonal $(U)$ and meridional winds $(V)$, air temperature $(T)$, and relative humidity $(R H)$. Although the radiosonde observations were used in the assimilation, we checked to what extent the assimilation result was close to the observations. Regarding the root mean 
(a)

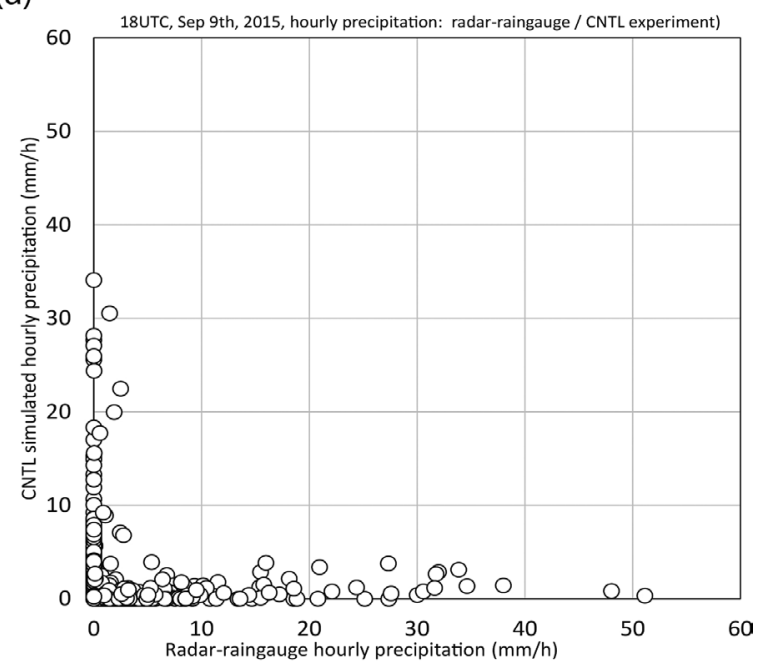

(b)

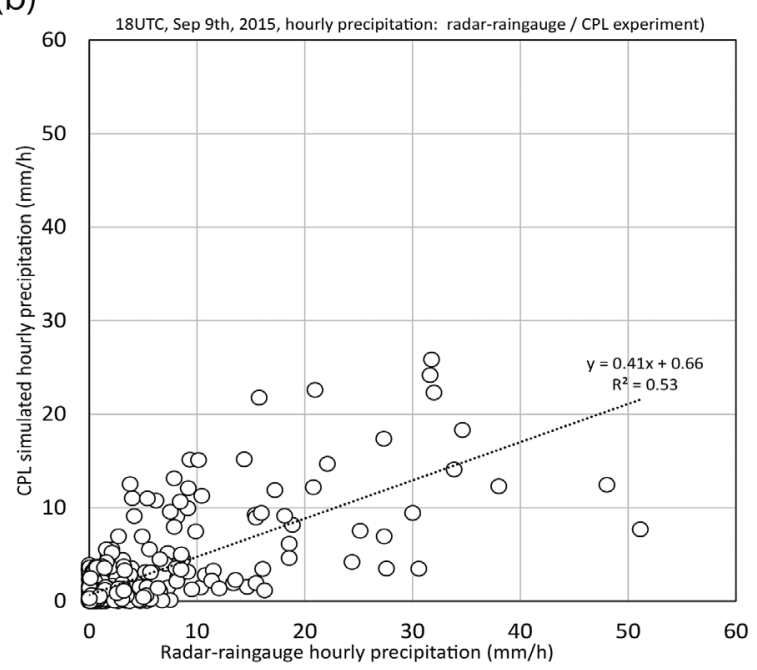

Fig. 9. Scatter diagrams of hourly radar-rain gauge analyzed rainfall $\left(\mathrm{mm} \mathrm{h}^{-1}\right)$ versus (a) hourly rainfalls $\left(\mathrm{mm} \mathrm{h}^{-1}\right)$ obtained in the CNTL experiment and (b) hourly rainfalls $\left(\mathrm{mm} \mathrm{h}^{-1}\right)$ obtained in the CPL experiment at 1800 UTC on 9 September in 2015. The dashed line in (b) indicates the linear correlation function. The correlation function with the second power of correlation coefficient is also shown in (b).

square error (RMSE) of $U, V, T$ and $R H$, RMSE in the CPL experiment was improved in the low-to-mid troposphere below the 500-hPa level (Fig. 11) except near the surface. The exception implies that there was a problem regarding the bias of air temperature in the CPL experiment, wherein the lowermost temperature

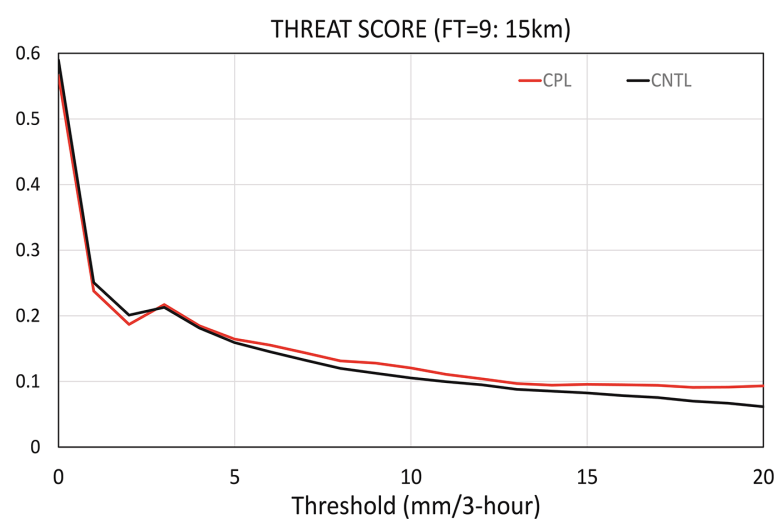

Fig. 10. Mean threat score for a threshold of 3-hourly precipitation amount from 0 to $20 \mathrm{~mm}$ per 3 hours averaged among 8 samples from 0000 UTC 9 to 1800 UTC 10 September every 6 hours.

became low and dry due to some problems associated with the surface boundary layer scheme and air-sea interfacial processes in the NHM. However, the atmospheric boundary processes played an essential role in the improvement in the low-to-mid troposphere below the $500-\mathrm{hPa}$ level. The improvement led to better expression of both the linear convective system and embedded local torrential rain occurred around $37^{\circ} \mathrm{N}$ in the Tochigi prefecture. The improvement in the analysis provides a more in-depth understanding of the formation mechanism of both the stationary linear convective system and local torrential rain.

\subsection{Etau and upper-tropospheric trough}

As shown in Fig. 2, Etau moved northward and became an extratropical cyclone in the Sea of Japan and then moved northeast over the ocean. Etau had a primary rainband (Houze 2010) in the eastern portion during the passage over the Japanese archipelago. After the passage, the rainband evolved into the stationary linearly convective system with embedded local torrential rain continuously around $37^{\circ} \mathrm{N}, 140^{\circ} \mathrm{E}$ in the Tochigi prefecture (Fig. 1). Here, we address the relationship between the extratropical transition of Etau and the linear convective system and the difference in the relationship between the CNTL and CPL experiments.

First, we address the effect of synoptic conditions on the linear convective system. To examine the impact of air-sea coupled assimilation on the synoptic conditions particularly in the upper troposphere, the concept of potential vorticity (PV) (e.g., Hoskins 

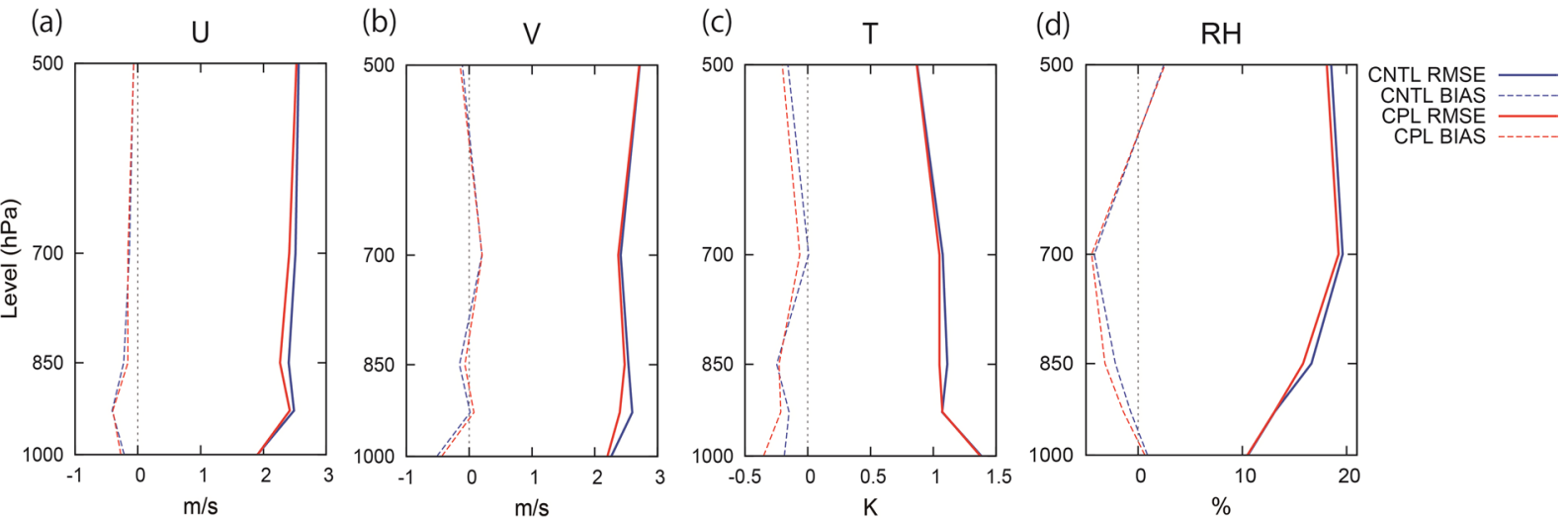

Fig. 11. Verifications of 6-h simulations relative to radiosonde observations for (a) a zonal $(U)$ and (b) meridional $(V)$ wind component $\left(\mathrm{m} \mathrm{s}^{-1}\right)$, (c) air temperature $(\mathrm{K})$, and $(\mathrm{d})$ relative humidity $(\%)$, averaged over 5 days from 0000 UTC 9 to 1800 UTC 13 September 2015. Solid and dashed lines correspond to RMSE and biases. Blue and red lines indicate the result in the CNTL and CPL experiments, respectively.

et al. 1985) is introduced. PV is proportional to the product of absolute vorticity and stability. Because it behaves as a flow tracer on an isentropic surface, the PV is an important concept that can be used to understand the effect of synoptic conditions such as upper-tropospheric trough on the linear convective system through the adiabatic process. In fact, PV has been utilized in studies on TC-trough interactions and transitioning TCs (e.g., Atallah et al. 2007).

According to RSMC best track data, Etau appeared over the ocean south of Japan at 0000 UTC 8 September (not shown). Figure 12 shows horizontal distributions of potential vorticity and winds on the $345 \mathrm{~K}$ isentropic surface together with sea-level pressures at 0000 UTC on 8 September, 0000 UTC and 1800 UTC on 9 September analyzed in the CNTL and CPL experiments. It should be noted that this study defines the center position of Etau as the point where the sea-level pressure is at a minimum. As shown in Fig. 12a, on the $345 \mathrm{~K}$ isentropic surface, southwesterly winds were strong at the southeastern side of the high PV region in the CNTL experiment. Etau moved along the southwesterly steering flow and made landfall in the central part of Japan at 0000 UTC 9 September (shown in a circle in Fig. 12b). At 1800 UTC, the extratropical cyclone was finally absorbed in the upper-tropospheric trough. The extratropical cyclone transited from Etau was stationary in the Sea of Japan (depicted as a typhoon mark in Fig. 12c) and then changed direction toward the northeast. The central pressure of the extratropical cyclone was 995.8 $\mathrm{hPa}$ at $1800 \mathrm{UTC}$ in the CNTL experiment.
Compared with the central pressure of Etau in the CNTL experiment (Fig. 12a), the central pressure in the CPL experiment was not significantly changed at 0000 UTC 8 September (Fig. 12d). However, the central pressure of Etau $(996.0 \mathrm{hPa})$ increased to some extent in the CPL experiment before the storm made landfall compared with the central pressure (995.1 $\mathrm{hPa}$ ) in the CNTL experiment (Fig. 12e). At 1800 UTC on 9 September, the central pressure of the extratropical cyclone (Fig. 12f) was higher $(998.3 \mathrm{hPa})$ in the CPL experiment than that $(995.8 \mathrm{hPa})$ in the CNTL experiment (Fig. 12c). Similar to the results in the CNTL experiment, the extratropical cyclone was absorbed in the upper-tropospheric trough. In Fig. 12, there was no significant difference in the distribution of the upper-tropospheric trough between the CNTL and CPL experiments, whereas there was a clear difference in the negative PV distribution on a meso-beta scale formed east of the upper-tropospheric trough.

Figure 13 shows the vertical sections of potential vorticity, winds, and potential temperature across the line A-B shown in Fig. 12, which were analyzed in the CNTL and CPL experiments. The upper-tropospheric trough and the meso-beta scale PV system moved from point A to B in Fig. 13. The meso-beta scale PV profile had an upstanding structure over the Japanese archipelago. The profile had a minimum in the lower troposphere and a maximum directly above in the CNTL experiment, while there was a maximum in the lower-to-mid troposphere and a minimum directly above in the CPL experiment where the linear convective system appeared. In the CPL experiment, 
(a)

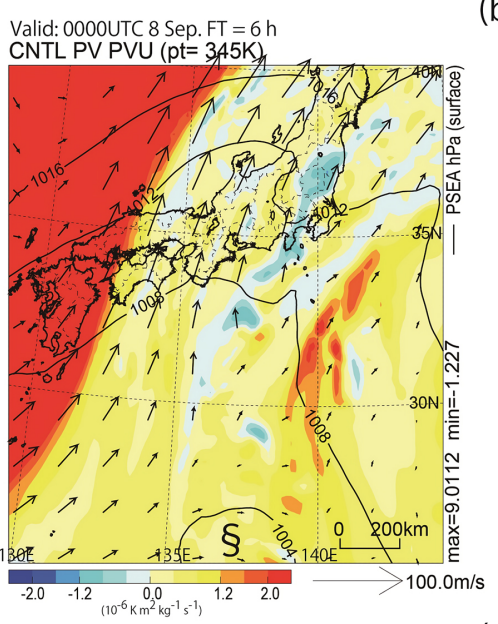

(d)

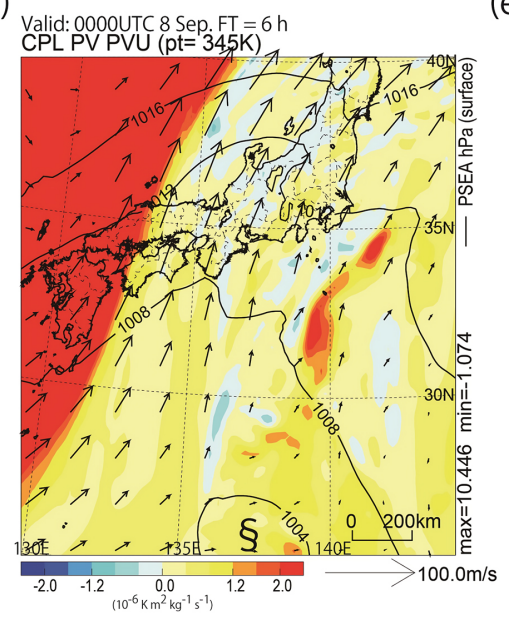

(b)

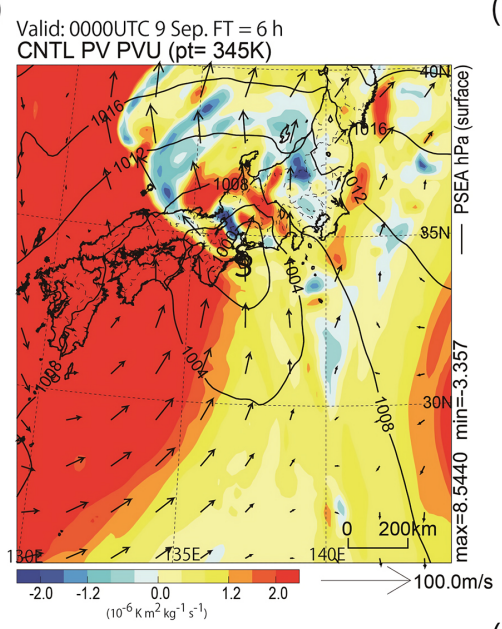

(e)

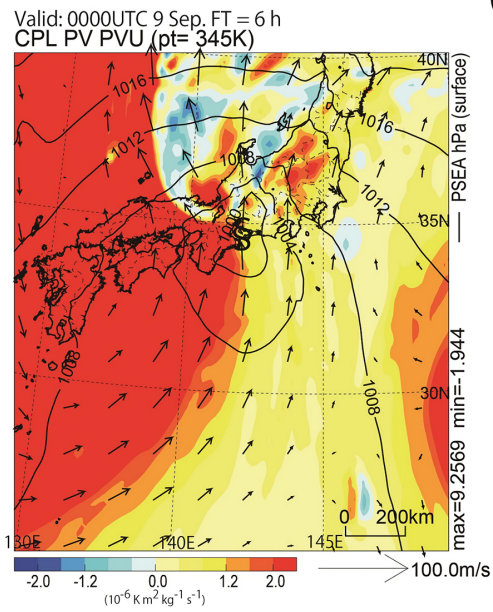

(c)

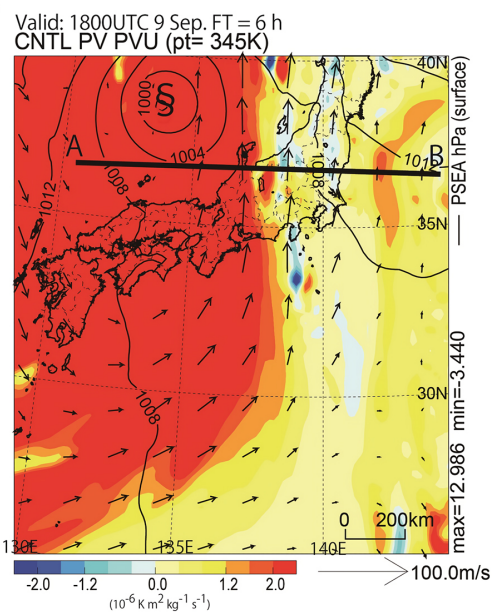

(f)

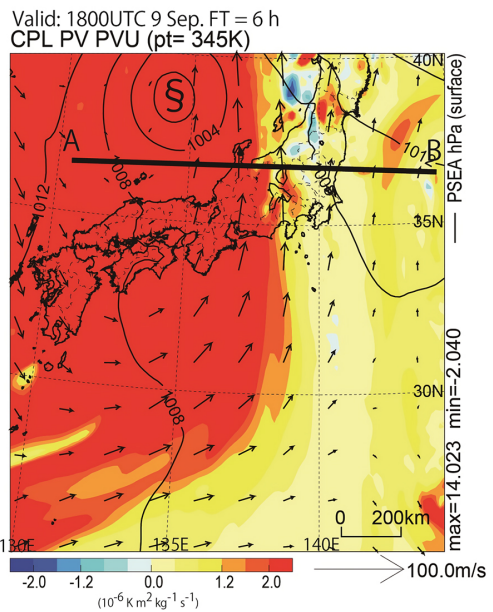

Fig. 12. Horizontal distributions of potential vorticity (colors) and winds (vectors) on the $345 \mathrm{~K}$ isentropic surface with sea-level pressures (contours at the interval of $4 \mathrm{hPa}$ ) analyzed in the CNTL experiment (a) at 00UTC on 8 September, (b) at 00 UTC and (c) at 18 UTC on 9 September and analyzed by the air-sea coupled NHM-LETKF system in the CPL experiment (d) at 00UTC on 8 September, (e) at 00 UTC and (f) at 18 UTC on 9 September. Black 'typhoon' marks indicate that location of a tropical cyclone or an extratropical cyclone. The potential vorticity unit is $1 \mathrm{PVU}\left(10^{-6} \mathrm{~K} \mathrm{~m}^{2} \mathrm{~kg}^{-1} \mathrm{~s}^{-1}\right)$. Black solid lines with characters ' $\mathrm{A}$ ' and ' $\mathrm{B}$ ' indicate the location of vertical cross section shown in Figs. 13 and 14.

the distribution of the lower-to-mid tropospheric maximum PV and directly above the minimum PV with respect to the creation of the updraft axis from the lower troposphere was consistent with a conceptual model reported by Fritsch et al. (1994) and Houze (2004), although these studies presented a model for explaining mesoscale convective vortex following a tropical cyclone. In the CNTL experiment, a mesobeta scale warm core structure also appeared as it did in the CPL experiment, although the height of the warm core became relatively high compared with that in the CPL experiment. The location of the minimum $\mathrm{PV}$ with the warm core corresponded to that of strong divergence on a meso-beta scale (Fig. 14). In the CPL experiment, a strong convergence area in the lower-tomid troposphere was located above the cold pool near the relatively strong lower tropospheric easterly. Also, the relatively high divergence area appeared west of the convergence area, which indicated the existence of outflow boundary conditions, which is consistent with the mesoscale convective system shown in the conceptual diagram in Fritsch et al. (1994) and Houze 
(a) Valid 1200UTC 9 Sep. FT $=6 \mathrm{~h}$

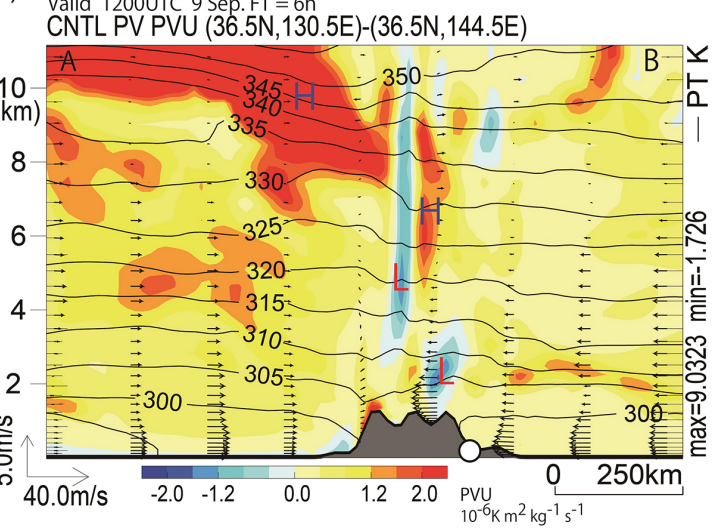

(b) Valid 1200UTC 9 Sep. FT $=6 \mathrm{~h}$

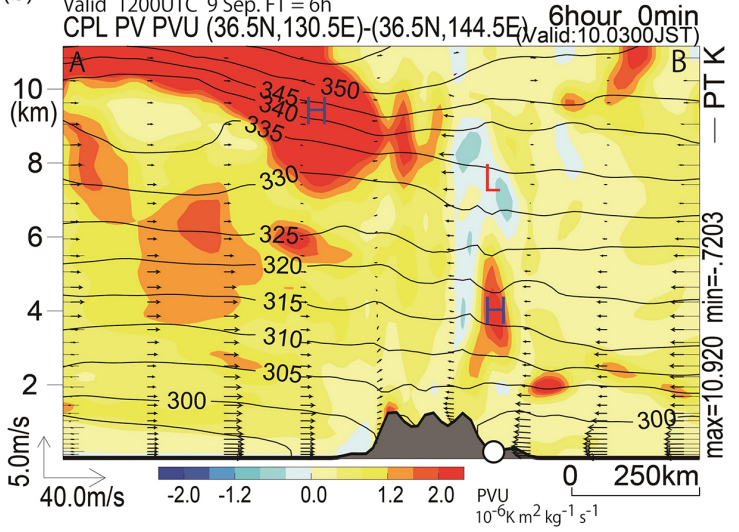

Fig. 13. Vertical sections of potential vorticity (colors) and winds (vectors) across the line A-B shown in Fig. 12 with potential temperatures (contours at the interval of $5 \mathrm{~K}$ ) (a) analyzed in the CNTL experiment and (b) analyzed by the air-sea coupled NHM-LETKF system in the CPL experiment. Red character 'L' shows the location of low PV, while blue ' $\mathrm{H}$ ' shows the location of high PV. An open black circle in each panel shows the location of the Tochigi prefecture.

(a)

Valid 1200UTC 9 Sep. $\mathrm{FT}=6 \mathrm{~h}$ Divergence $(36.5 \mathrm{~N}, 130.5 \mathrm{E})-(36.5 \mathrm{~N}, 144.5 \mathrm{E})$

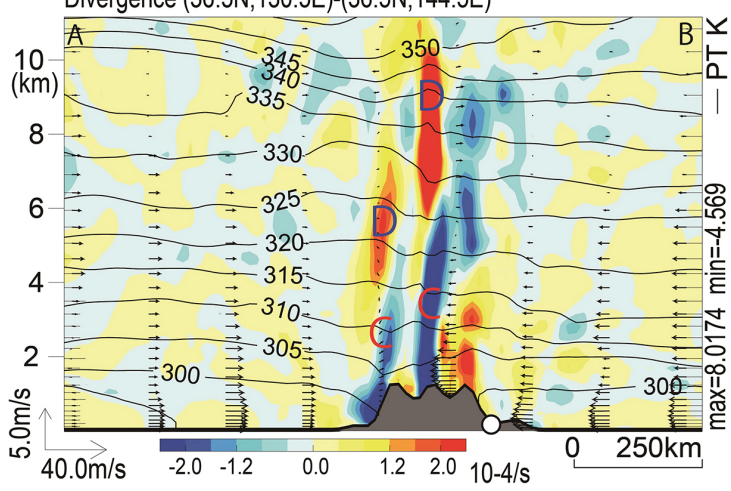

(b)

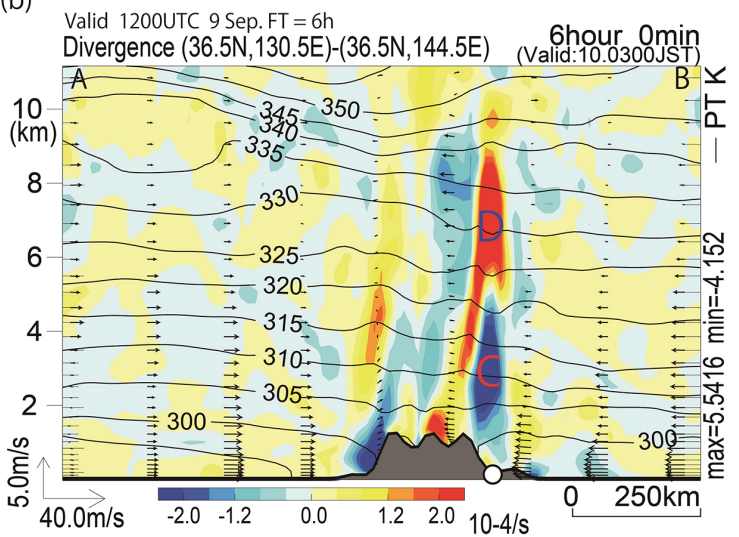

Fig. 14. Same as Fig. 13 except for divergence. Cool colors indicate the convergence area, while warm colors indicate the divergence area. Red character ' $C$ ' shows the location of relatively strong convergence, while blue ' $D$ ' shows the location of relatively strong divergence.

(2004). In addition, the vertical wind profile west of the PV maximum/minimum pattern found in the CPL experiment was also consistent with the environmental vertical wind shear, as the profile had a deep layer of weak flow and weak shear in the mid-to-upper troposphere (Fritsch et al. 1994; Houze 2004). Using the air-sea coupled data assimilation, the meso-beta scale PV may be modified through a change in environmental vertical wind profiles.
3.4 Lower-tropospheric moisture flux and convection As described in Section 3.3, the meso-beta scale PV distribution was changed when the coupled NHM-LETKF was used as a data assimilation system (Fig. 7). In particular, lower-tropospheric winds associated with environmental vertical wind shear and formation of an updraft are important because they directly affect estimates of turbulent heat fluxes, horizontal moisture transport in the lower troposphere, and variations in SST. This section addresses the effect of analyzed SST on the lower-tropospheric 
moisture fluxes and associated convection. The lowertropospheric moisture flux was calculated by specific humidity multiplying a horizontal wind speed at each grid and level, while convection was detected based on upward vertical velocity. Tsuguti and Kato (2014a) pointed out the importance of lower-tropospheric moist airs and air-mass transformation associated with high SST and air-sea latent heat flux to the formation and maintenance of the heavy rainfall event occurred on Amami-Oshima Island, Japan in 2010 when Typhoon Megi (2010) made landfall in the Philippines and moved to the South China Sea. Yoshida and Itoh (2012) reported that a large moisture flux south of
Kyushu led to a heavy rainfall event in the vicinity of Kyushu when Typhoon Maggie (1999) caused the northward advection of a separate tropical disturbances during the northwestward translation.

The horizontal moisture fluxes in the CNTL (Fig. 15a) and CPL (Fig. 15b) experiments were relatively high around the extratropical cyclone, along the linear convective system and east of the linear convective system north of $30^{\circ} \mathrm{N}$. South of Japan, by contrast, horizontal moisture fluxes analyzed in the CPL experiment were relatively low $\left(<50 \mathrm{~g} \mathrm{~m}^{-2} \mathrm{~s}^{-1}\right)$ compared with those in the CNTL experiment. The vertical cross section across the Japanese archipelago in the (a)

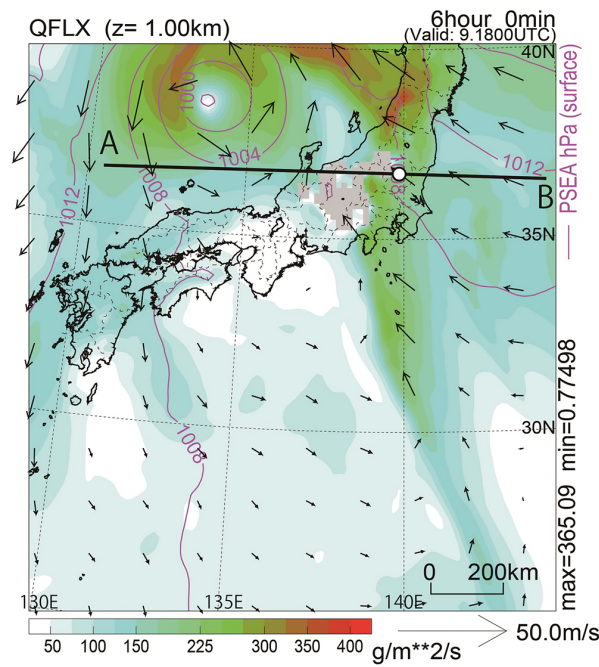

(c)

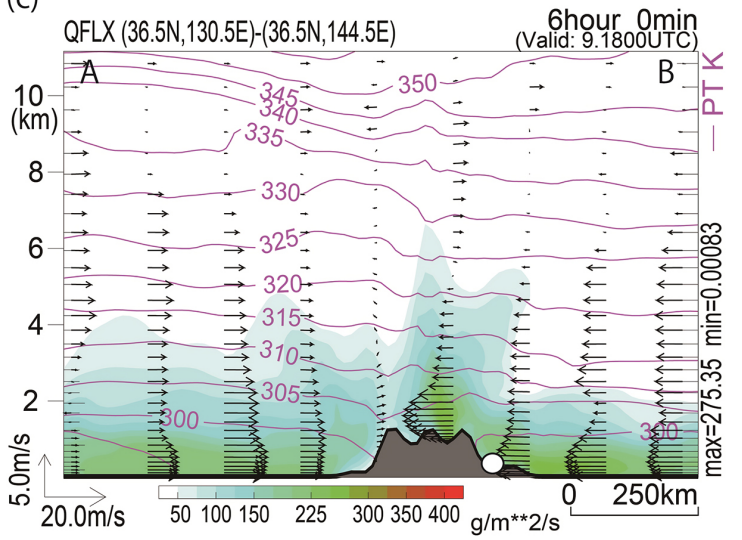

(b)

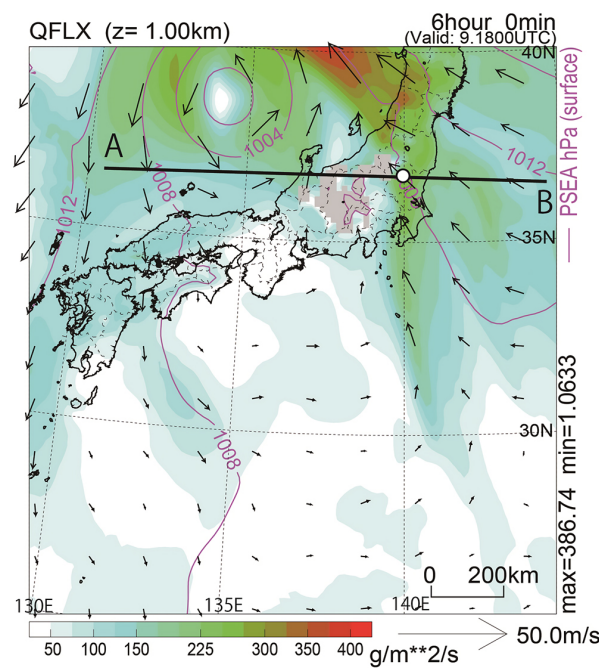

(d)

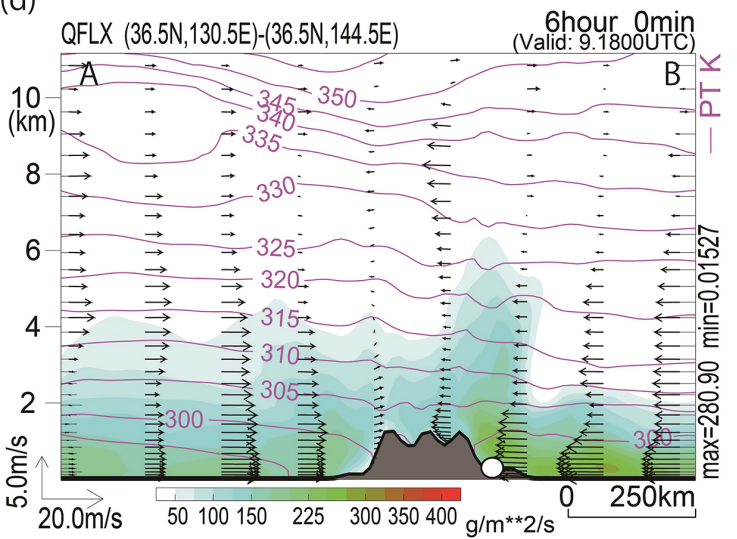

Fig. 15. Horizontal distributions of horizontal moisture flux at $1000 \mathrm{~m}$ height at 0000 UTC 10 September 2015 in (a) the CNTL and (b) the CPL experiments. Contours indicates sea-level pressures with an interval of $4 \mathrm{hPa}$. Black solid lines with characters ' $A$ ' and ' $B$ ' indicate the location of vertical cross section. Vertical cross sections of horizontal moisture flux in the (c) CNTL and (d) CPL experiments. Contours indicates potential temperatures with an interval of $5 \mathrm{~K}$. Vectors show winds along the A-B Line. In (a)-(d), shades indicate horizontal moisture flux. An open black circle in each panel shows the location of the Tochigi prefecture. 
CNTL experiment (Fig. 15c) indicates that the lowertropospheric horizontal moisture flux transported from east of Japan to the Japanese archipelago was stronger than that transported from west of Japan. The lower-tropospheric convergence resulted in upward moisture flux in the middle and east of the Japanese archipelago. The upward moisture transport was only analyzed east of the Japanese archipelago in the CPL experiment (Fig. 15d) due to relatively weak lowertropospheric easterly winds (Fig. 11b). The difference in winds at $20-\mathrm{m}$ height between the CNTL and CPL experiments clearly increased around the location of the linearly convective system (Fig. 16). This led to increases in the difference of the lower-tropospheric convergence. In fact, air-sea latent heat fluxes were relatively high around the extratropical cyclone, the linear convective system, and Kilo in the CNTL experiment (Fig. 17a), while air-sea latent heat fluxes decreased around these areas in the CPL experiment (Fig. 17b). In particular, the reduction in air-sea latent heat fluxes around the extratropical cyclone and Kilo was caused by storm-induced sea surface cooling in the CPL experiment. In the coupled NHM-LETKF, the storm-induced sea surface cooling could be predicted

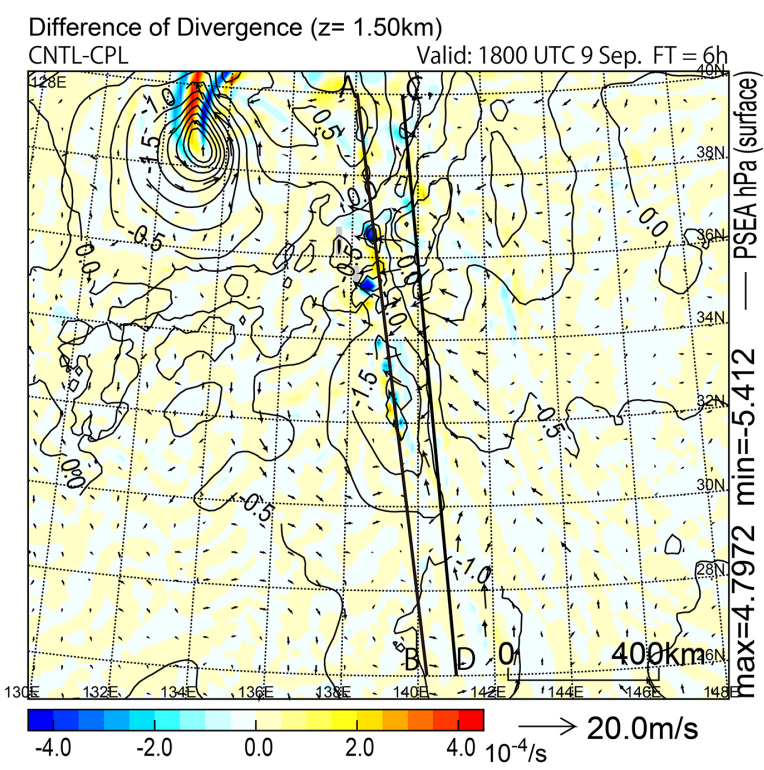

Fig. 16. Horizontal distribution of the difference in sea-level pressure (contours), winds at 20-m height (vectors) and divergence at 1500-m height between CNTL and CPL experiments at 1800 UTC on 9 September. Black solid lines with characters ' $\mathrm{A}$ ' and ' $\mathrm{B}$ ' indicate the location of vertical cross section in the CNTL experiment shown in Fig. 18 , while those with characters ' $\mathrm{C}$ ' and ' $\mathrm{D}$ ' indicate the location of vertical cross section in the CPL experiment shown in Fig. 19. (a)

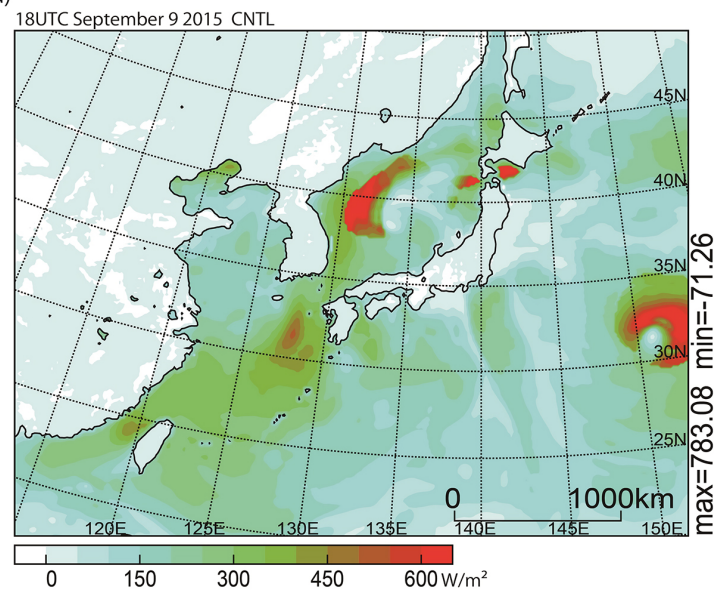

(b)

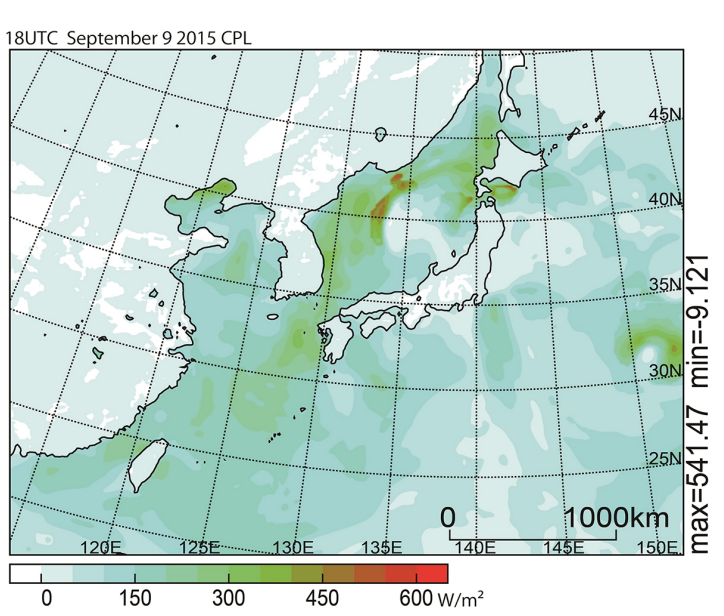

Fig. 17. Horizontal distributions of air-sea latent heat flux (colors) (a) analyzed in the CNTL experiment and (b) analyzed by the air-sea coupled NHM-LETKF system in the CPL experiment. 

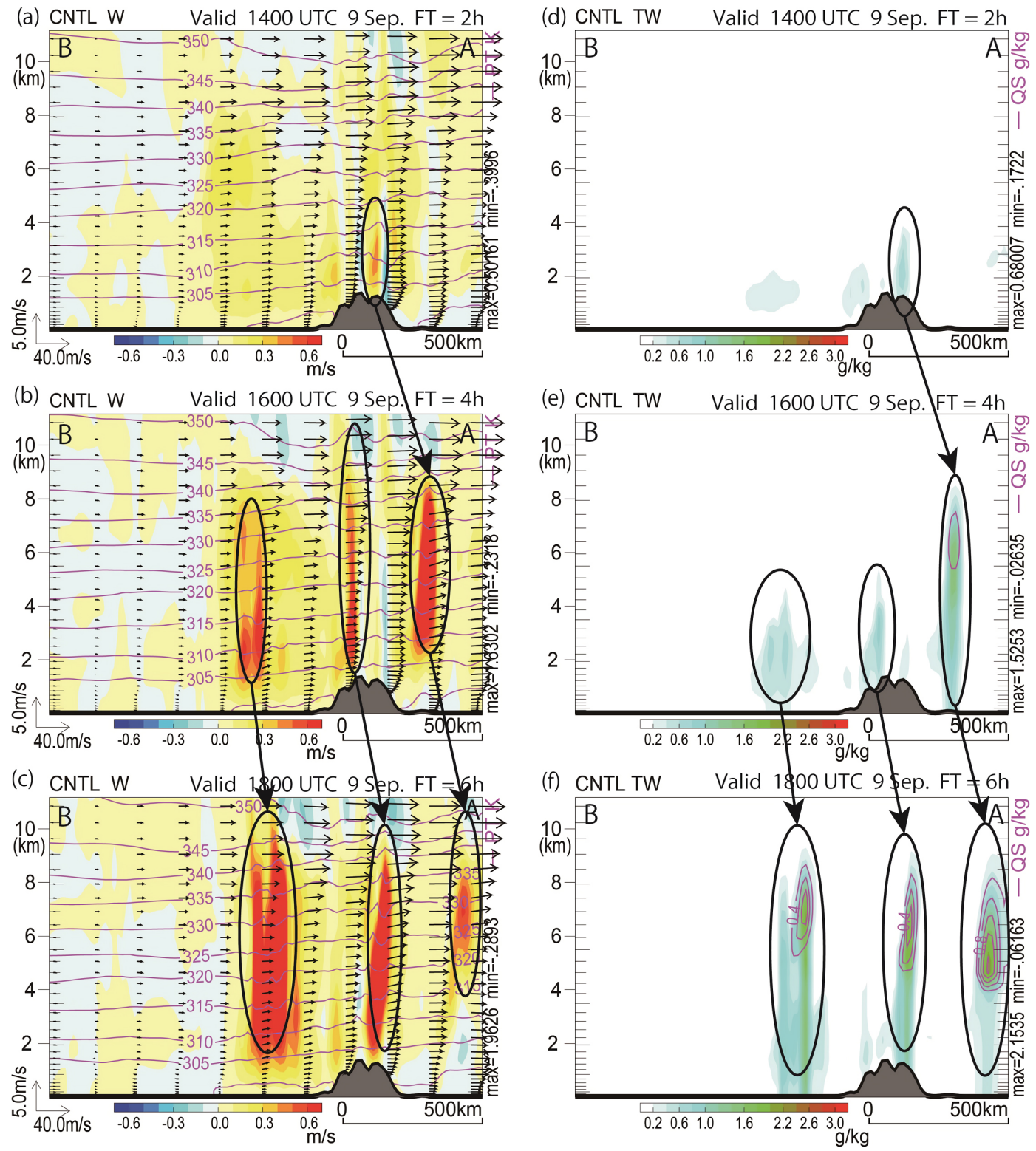

Fig. 18. Vertical sections across the line A-B of vertical wind velocity at (a) 1400 UTC (corresponding to twohour forecast time), (b) 1600 UTC (corresponding to four-hour forecast time) and (c) 1800 UTC (corresponding to six-hour forecast time) and those of total water content (colors) with specific humidity for snow (contours at the interval of $0.4 \mathrm{~g} \mathrm{~kg}^{-1}$ ) at (d) 1400 UTC (corresponding to two-hour forecast time), (e) 1600 UTC (corresponding to four-hour forecast time) and (f) 1800 UTC (corresponding to six-hour forecast time) in the CNTL experiment.

by the atmosphere-wave-ocean coupled model even under deep cloud conditions (Wada and Kunii 2017). The reduction in air-sea latent heat fluxes in the CPL experiment not only led to decrease in the lowertropospheric equivalent potential temperature but also a change in the horizontal distribution of the lower- tropospheric equivalent potential temperature (not shown). The change did affect the horizontal moisture fluxes in the lower troposphere, and the differences between the CNTL and CPL experiments are one of the factors that could change the location of the linear convective system. 
(a) CPL W Valid 1400 UTC 9 Sep. FT $=2 \mathrm{~h}$

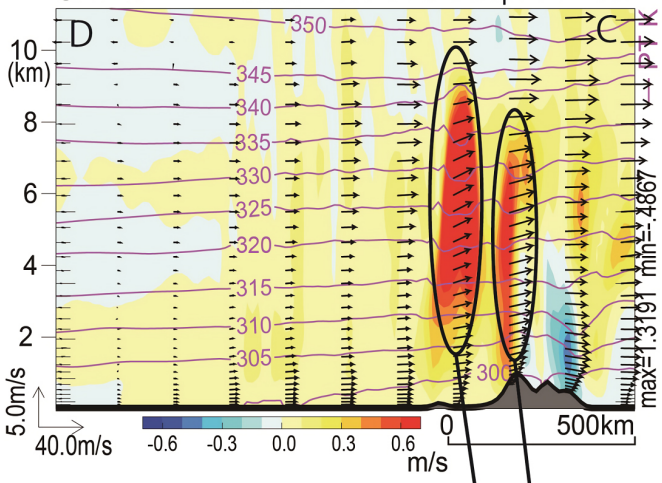

(b) CPL W Valid 1600 UTC 9\$ep. $\mathrm{FT}=4 \mathrm{~h}$
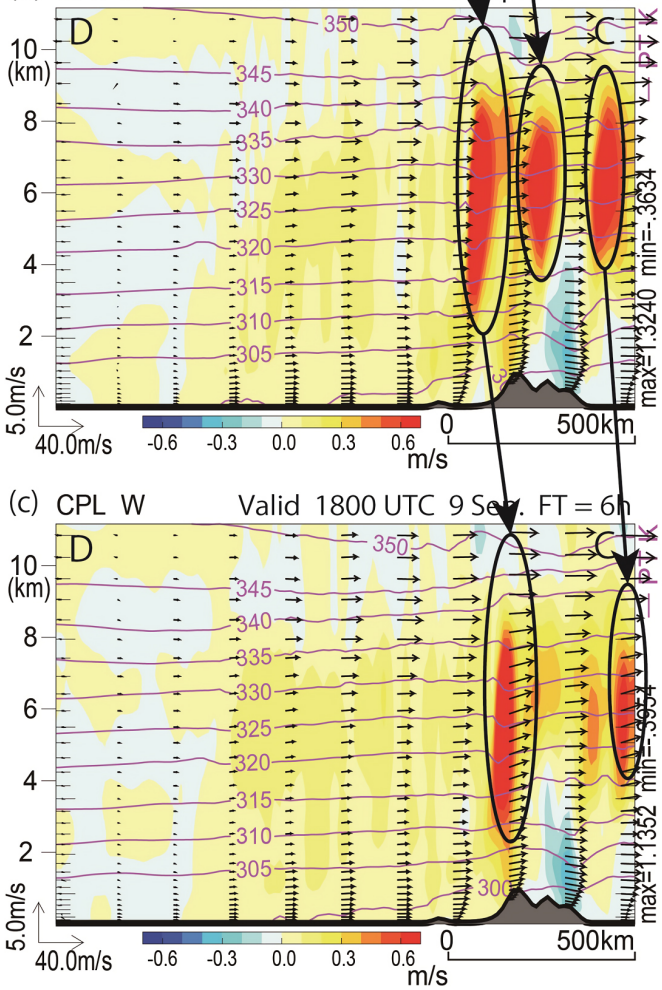

(d) CPL TW Valid 1400 UTC 9 Sep. FT $=2 \mathrm{~h}$

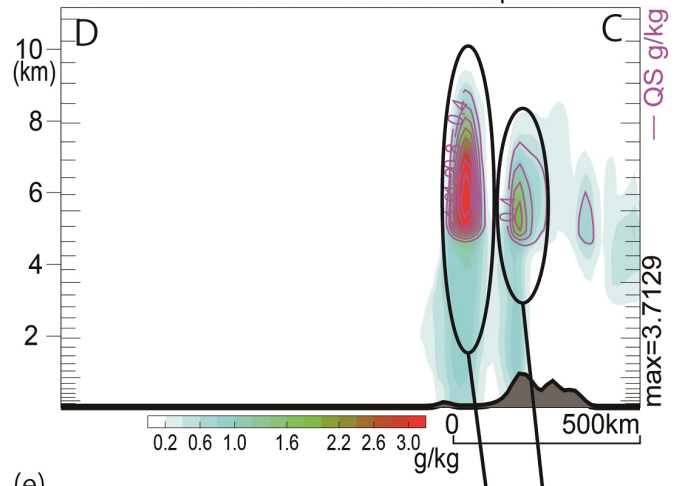

(e)

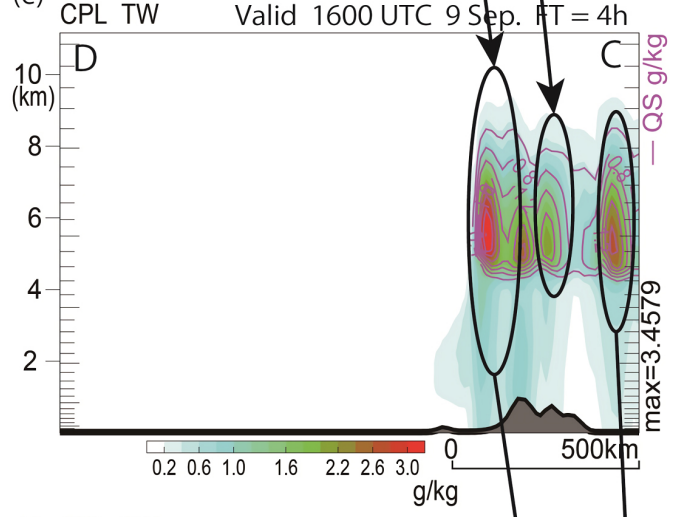

(f) CPL TW Valid 1800 UTC 9 Sep LFT $=61$

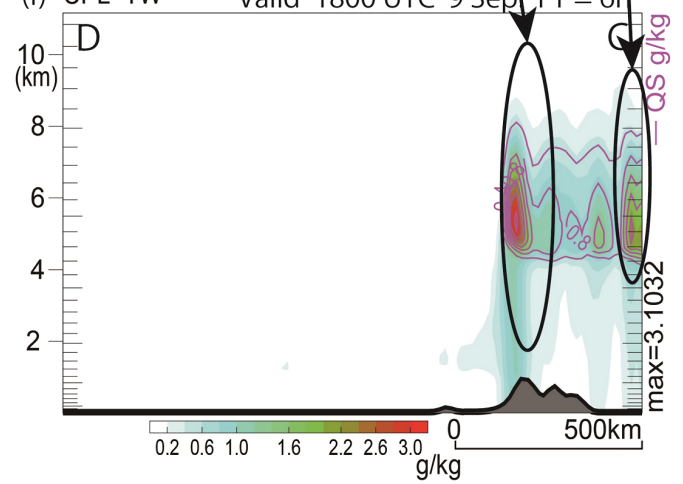

Fig. 19. Same as Fig. 18 except across the line C-D in the CPL experiment.

Hereafter, this section focuses on the linear convective systems calculated in the CNTL and CPL experiments. Both linear convective systems in the CNTL and CPL experiments were sustained within a cycle of data assimilation (for 6 hours). Vertical cross sections of vertical wind velocity and total water content (defined as a summation of rain, cloud, snow, ice, and graupel) and their evolution are shown along the linear convective system in the CNTL (Fig. 18) and CPL (Fig. 19) experiments. The area of relatively high upward vertical velocity, representing the occurrence of convection, corresponded to the area where total water content was high. The total water content became high at a height of around 6-km in the CPL experiment because of an increase in snow. Arrows in Figs. 18 and 19 indicate that the convective area with high total water content extended northward (from ' $\mathrm{B}$ ' to 'A' in Fig. 18 and from ' $\mathrm{D}$ ' to ' $\mathrm{C}$ ' in Fig. 19) like a wave train that propagated to the downstream (' $A$ ' in Fig. 18 and ' $C$ ' in Fig. 19) side. The wave 
train began to become enhanced over the Japanese archipelago where southerly winds became strong at the southeastern edge of the upper-tropospheric trough (Figs. 12c, f). A single cell was dominant in the CNTL experiment, while the cells seemed to be linked as a stationary linearly convective system in the CPL experiment. In other word, the moving speed of a convective cell in the CNTL experiment was faster than that in the CPL experiment. The relatively fast moving speed was related to the relatively fast southerly winds throughout the vertical profile in the CNTL experiment (Fig. 18). It should be noted that the area of high total water content appeared locally in the horizontal distribution (not shown), indicating that the effect of the horizontal advection on the occurrence of high total water content was relatively small. Around the Tochigi prefecture, negative vertical wind velocity was continuously found in the lower troposphere (Figs. $19 \mathrm{a}-\mathrm{c})$. In addition, the convergence was relatively strong, and a deep layer of weak flow existed in the mid-to-upper troposphere around the Tochigi prefecture (Fig. 14). This indicated a stationary stratiform area formed around the location of local torrential rain.

Roles of upper-tropospheric trough, lower-tropospheric winds and the SST field in formation, and maintenance of the linearly convective system are summarized in Fig. 20. The upper-tropospheric trough, lower-tropospheric winds, and SST field modified by the coupled NHM-LETKF played an important role in determining the location of the lower-tropospheric convergence area, as well as the occurrence and maintenance of the linearly convective system. It should be noted that easterly winds associated with Kilo were closely related to the transport of the lowertropospheric moisture fluxes toward the linear convective system that played a crucial role in determining the location of the convergence area over the Japanese archipelago, although the difference in the easterly winds between CNTL and CPL was small. The linearly convective system in the CPL experiment had a common characteristic with that assimilated in the CNTL experiment. Specifically, the convective area extended south to north like a wave train over the Japanese archipelago due to strong winds at the eastern side of the upper-tropospheric trough. In addition, the system was sustained for six hours in both the CNTL and CPL experiments. The difference between the two experiments appeared not only in the location of the linear convective system but also in the lower-troposphere, where negative vertical winds were sustained and local torrential rain occurred.
Therefore, more accurate SST analysis by the coupled NHM-LETKF leads to improvements in analyzing the location of the linearly convective system with the embedded local torrential rain occurred between Kilo and the extratropical cyclone transited from Etau. This is consistent with the effect of lowertropospheric moisture (Peters et al. 2017; Schumacher 2015; Schumacher and Peters 2017) on the formation, location, and longevity of the linear convective system. In addition, the area of high lower-tropospheric moisture in the Pacific Ocean corresponded to the area of high equivalent potential temperature (not shown). In that sense, warm air advection (Peters and Schumacher 2015a, b) also has important effect on the formation, location, and longevity of the linear convective system.

\section{Discussion}

The impact of SST modification due to ocean coupling on the lower troposphere is considered to be generally small on a weather-forecasting time scale except for severe weather such as tropical cyclones. The impact of the storm-induced oceanic response (Price 1981) on tropical cyclones differs from that of preexisting synoptic SST conditions on atmospheric disturbances. The latter has ever been investigated synoptically for heavy rainfalls under the Asian summer monsoon (Manda et al. 2014), storm tracks (Kuwano-Yoshida and Minobe 2017; Sasaki et al. 2012), and extratropical cyclones (Xu et al. 2011). In addition, this has been examined using an atmosphere-ocean coupled model (e.g., Berthou et al. 2014; Lebeaupin Brossier et al. 2013). These studies have found that local changes in SST and the differences in SST fields such as the horizontal SST gradient have some impacts on the atmosphere. The effect of a change in the SST field analyzed every cycle of the data assimilation by the coupled NHM-LETKF with AMSR2 L2 SST is essentially consistent with the results reported in these previous studies. This study implicitly supports the idea that the ocean plays an active role in driving the atmosphere (e.g., Small et al. 2008; Kelly et al. 2010; Kwon et al. 2010).

However, sea surface cooling and reduction in airsea latent heat flux by passage of Etau and Kilo can be understood as the occurrence of 'negative feedback' effects caused by the oceanic response to tropical cyclones (e.g., Chang and Anthes 1979; Zhu et al. 2004; Wu et al. 2005; Bender et al. 2007; Wada 2009; Wada et al. 2010, 2014; Kanada et al. 2017). The coupled NHM-LETKF with AMSR2 L2 SST realistically reproduced sea surface cooling so that the analysis of 

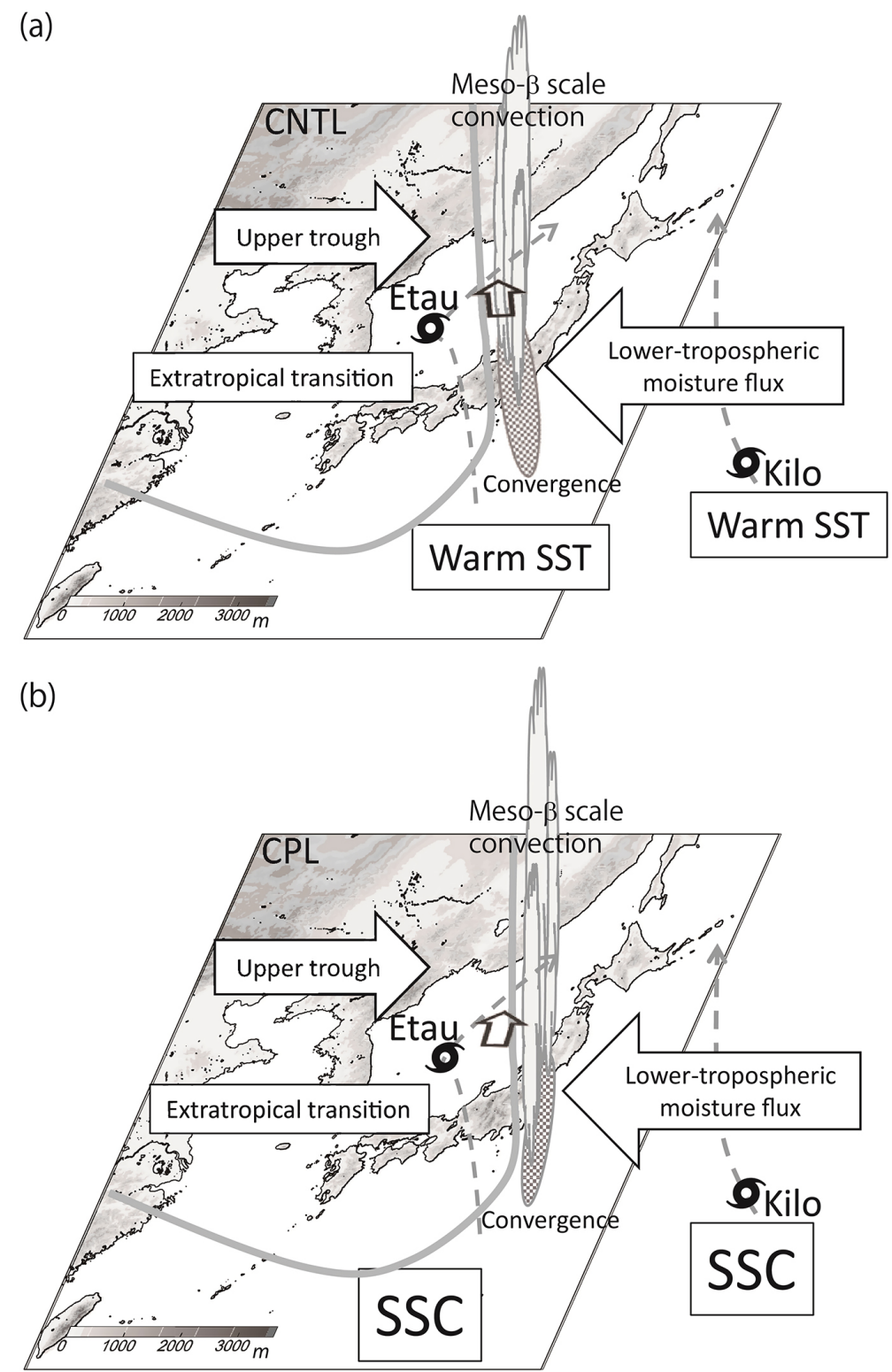

Fig. 20. Schematic diagram on the linear convective system between Typhoons Kilo and Etau in September 2015 through the horizontal distributions of the upper-tropospheric trough, SST and the location of convergence in the lower troposphere caused by southerly winds associated with Etau and easterly winds associated with Kilo in the (a) CNTL experiment and (b) CPL experiment, respectively.

the SST field was improved.

In this study, no bias correction was conducted for AMSR2 L2 SST when running the 6-hour cycle of the analysis by the coupled NHM-LETKF with AMSR2 L2 SST, although the verification result shown in Fig. 5 was reasonable for the analyzed SST. In fact, the ocean model in the atmosphere-wave-ocean coupled model used in this study has a problem simulating a diurnal cycle of SST. A more realistic analysis of a diurnal cycle of SST in the CPL experiment may lead to an improvement in the analysis of SST. The improvement of the analysis of SST will lead to an improvement in the location of the linearly convective system and the strength of local torrential rainfall. 
It should be noted that it was necessary to spin up about one week for analyzed SST to become consistent with the observed SST (Wada and Kunii 2017). The amount of the observation data (the amount of AMSR2 L2P SST per cycle of the analysis in this study) may be related to this spin-up period in view of the rate of data coverage to the analysis region. When performing target observation like the Observing System and Predictability Experiment (THORPEX) Pacific Asian Regional Campaign (T-PARC) (see Wada and Kunii 2017) and conducting both atmospheric and oceanic analyses using the coupled NHMLETKF or another air-sea strongly coupled data assimilation system, it is necessary to use an adequate amount of spin-up time.

This study demonstrates that improvement of the lower troposphere by improving the SST analysis contributed to the improvement of the analysis of the September 2015 Kanto-Tohoku heavy rainfall. This suggests that synoptic SST field and the lower troposphere play a crucial role in the formation and maintenance of the linear convective system. However, the role that SST played in the accuracy of the analysis of the linear convective system might be changed when the horizontal resolution of NHM-LETKF (15 $\mathrm{km}$ ) becomes high (e.g., $5 \mathrm{~km}$ or less) and a cumulus convection scheme is not used in a forecast model. Moreover, this type of regional data assimilation system is greatly influenced by the lateral boundary conditions when analyzing the stagnation/deformation processes of the upper trough, which is considered to play a crucial role in the stagnation of the linear convective system and associated local torrential rain (Kitabatake et al. 2017). Due to the constraint of computational resources, in the present study, it is difficult to identify the relationship between the stagnation and deformation processes to the upper-tropospheric trough and the linear convective system. To clarify this relationship, we expect that a global air-sea coupled data assimilation system will be developed in the future.

\section{Concluding remarks}

In September 2015, the linear convective system that originated from the primary rainband of Typhoon Etau stagnated and caused local torrential rain continuously around $37^{\circ} \mathrm{N}, 140^{\circ} \mathrm{E}$ in the Tochigi prefecture on 9-10 September. The area of the linear convective system moved near the Tohoku region on 11 September. The linear convective system occurred between Typhoon Kilo and the extratropical cyclone transited from Etau (Fig. 2). This study addresses the effect of the sea surface temperature (SST) analysis on the analysis and prediction of the linear convective system with embedded local torrential rain using the air-sea coupled data assimilation system based on a local ensemble transform Kalman filter (LETKF), a nonhydrostatic atmosphere model (NHM) coupled with ocean-surface wave model and a multilayer ocean model, and Advanced Microwave Scanning Radiometer 2 (AMSR2) level 2 (L2) SST data. This study also addresses the difference in the relationship of Kilo and the extratropical cyclone transited from Etau to the linear convective system by applying the air-sea strongly coupled data assimilation system based on NHM-LETKF (Kunii 2014), but the forecast portion of the original system is replaced with an atmosphere-wave-ocean coupled model (coupled NHM-LETKF).

The analysis of SST is improved by the coupled NHM-LETKF with AMSR2 L2 SST for Kilo, Etau, and the September 2015 Kanto-Tohoku heavy rainfall events. In addition, the coupled NHM-LETKF with AMSR2 L2 SST successfully improved the precipitation forecasts of the stationary linear convective system with embedded local torrential rain. The coupled NHM-LETKF could change the extratropical cyclone transited from Etau but also change the synoptic field associated with the lower-tropospheric dynamic/thermodynamic conditions, although there was no significant difference in the upper-tropospheric trough. These changes result in the difference of the analyzed location of the linear convective system. The synoptic SST field did affect the location of lowertropospheric convergence area with changes in air-sea latent heat fluxes and equivalent potential temperature in the lower troposphere.

The SST analysis by the coupled NHM-LETKF was validated with in situ observations and MTSAT-2 SST. The correlation of SST analyzed by the coupled NHM-LETKF with in-situ observations and MTSAT2 SST was significantly higher than that of SST used in the original NHM-LETKF. The improvement of SST analysis led to the improvement of atmospheric analysis particularly in the lower troposphere. The improvement of the analyses of both SST and the lower troposphere is important to improve the analysis of the linearly convective system with the embedded local torrential rain. It should be noted that a problem regarding the bias of air temperature remains, resulting in the lowermost temperature becoming low and dry. To improve the analysis of air temperature near the surface using NHM-LETKF, we need to improve the surface boundary layer scheme and air-sea interfa- 
cial processes in the NHM.

Extremely heavy rainfall events are very rare, so that it is difficult to compile case studies to verify the effectiveness of the coupled NHM-LETKF. However, with respect to tropical cyclones, the number of genesis is on the order of 20-30 in the western North Pacific. It is necessary to compile case studies of severe weather such as tropical cyclones to further develop the coupled NHM-LETKF. In addition, predictability studies regarding tropical cyclones and extremely heavy rainfall events using the coupled NHM-LETKF with new datasets obtained from new observational technologies, such as more sophisticated satellite observations (e.g., Bessho et al. 2016; Ruf et al. 2016) and new in situ observations (e.g., Yonehara et al. 2016; Wada et al. 2017), will contribute to the progress of weather forecasts using an advanced numerical prediction system.

\section{Acknowledgments}

We would like to express our appreciation to the two anonymous reviewers for their insightful comments that helped improve the manuscript. This study was supported by the Japan Society for the Promotion of Science Grants-in-Aid for Scientific Research (KAKENHI) grant number, 15K05292 and 17H02964. This paper is based on the achievements of the collaborative research program (28K-05) of the Disaster Prevention Research Institute of Kyoto University. The authors thanks Dr. R. Oyama for supporting the analysis of MTSAT SST. AMSR2 L2P SST was supplied by the GHRSST Server, Japan Aerospace Exploration Agency.

\section{References}

Atallah, E., L. F. Bosart, and A. R. Aiyyer, 2007: Precipitation distribution associated with landfalling tropical cyclones over the Eastern United States. Mon. Wea. Rev., 135, 2185-2206.

Bauer, P., A. Thorpe, and G. Brunet, 2015: The quiet revolution of numerical weather prediction. Nature, 525, $47-54$.

Bender, M. A., I. Ginis, R. Tuleya, B. Thomas, and T. Marchok, 2007: The operational GFDL coupled hurricane-ocean prediction system and a summary of its performance. Mon. Wea. Rev., 135, 3965-3989.

Berthou, S., S. Mailler, P. Drobinski, T. Arsouze, S. Bastin, K. Béranger, and C. Lebeaupin-Brossier, 2014: Sensitivity of an intense rain event between atmosphereonly and atmosphere-ocean regional coupled models: 19 September 1996. Quart. J. Roy. Meteor., 141, 258271.

Bessho, K., K. Date, M. Hayashi, A. Ikeda, T. Imai, H.
Inoue, Y. Kumagai, T. Miyakawa, H. Murata, T. Ohno, A. Okuyama, R. Oyama, Y. Sasaki, Y. Shimazu, K. Shimoji, Y. Sumida, M. Suzuki, H. Taniguchi, H. Tsuchiyama, D. Uesawa, H. Yokota, and R. Yoshida, 2016: An introduction to Himawari-8/9_Japan's new-generation geostationary meteorological satellites. J. Meteor. Soc. Japan, 94, 151-183.

Brunet, G., M. Shapiro, B. Hoskins, M. Moncrieff, R. Dole, G. N. Kiladis, B. Kirtman, A. Lorenc, B. Mills, R. Morss, S. Polavarapu, D. Rogers, J. Schaake, and J. Shukla, 2010: Collaboration of the weather and climate communities to advance subseasonal-to-seasonal prediction. Bull. Amer. Meteor. Soc., 91, 1397-1406.

Chang, S. W., and R. A. Anthes, 1979: The mutual response of the tropical cyclone and the ocean. J. Phys. Oceanogr., 9, 128.

Fritsch, J. M., J. D. Murphy, and J. S. Kain, 1994: Warm core vortex amplification over land. J. Atmos. Sci., 51, 1780-1807.

Honda, T., S. Kotsuki, G.-Y. Lien, Y. Maejima, K. Okamoto, and T. Miyoshi, 2018: Assimilation of Himawari-8 all-sky radiances every 10 minutes: Impact on precipitation and flood risk prediction. J. Geophys. Res., 123, 965-976.

Hoskins, B. J., M. E. McIntyre, and A. W. Robertson, 1985: On the use and significance of isentropic potential vorticity maps. Quart. J. Roy. Meteor., 111, 877-946.

Houze, R. A., Jr., 2004: Mesoscale convective systems. Rev. Geophys., 42, RG4003, doi:10.1029/2004RG000150.

Houze, R. A., Jr., 2010: Clouds in tropical cyclones. Mon. Wea. Rev., 138, 293-344.

Kanada, S., S. Tsujino, H. Aiki, M. K. Yoshioka, Y. Miyazawa, K. Tsuboki, and I. Takayabu, 2017: Impacts of SST patterns on rapid intensification of Typhoon Megi (2010). J. Geophys. Res., 122, 13245-13262.

Kawai, Y., and A. Wada, 2007: Diurnal sea surface temperature variation and its impact on the atmosphere and ocean: A review. J. Oceanogr., 63, 721-744.

Kelly, K. A., R. J. Small, R. M. Samelson, B. Qiu, T. M. Joyce, Y.-O. Kwon, and M. F. Cronin, 2010: Western boundary currents and frontal air-sea interaction: Gulf Stream and Kuroshio Extension. J. Climate, 23, 5644-5667.

Kitabatake, N., H. Tsuguti, and T. Kato, 2017: Effects of synoptic-scale environmental flows on the heavy rainfall event in the Kanto and Tohoku District in September 2015. Tenki, 64, 887-899 (in Japanese).

Kunii, M., 2014: Mesoscale data assimilation for a local severe rainfall event with the NHM-LETKF system. Wea. Forecasting, 29, 1093-1105.

Kunii, M., and T. Miyoshi, 2012: Including uncertainties of sea surface temperature in an ensemble Kalman filter: A case study of Typhoon Sinlaku (2008). Wea. Forecasting, 27, 1586-1597.

Kunii, M., M. Otsuka, K. Shimoji, and H. Seko, 2016: Ensemble data assimilation and forecast experiments 
for the September 2015 heavy rainfall event in Kanto and Tohoku regions with atmospheric motion vectors from Himawari-8. SOLA, 12, 209-214.

Kunii, M., K. Ito, and A. Wada, 2017: Preliminary test of a data assimilation system with a regional high-resolution atmosphere-ocean coupled model based on an ensemble Kalman filter. Mon. Wea. Rev., 145, 565581.

Kunoki, S., A. Manda, Y.-M. Kodama, S. Iizuka, K. Sato, I. Fathrio, T. Mitsui, H. Seko, Q. Moteki, S. Minobe, and Y. Tachibana, 2015: Oceanic influence on the Baiu frontal zone in the East China Sea. J. Geophys. Res., 120, 449-463.

Kurihara, Y., T. Sakurai, and T. Kuragano, 2006: Global daily sea surface temperature analysis using data from satellite microwave radiometer, satellite infrared radiometer and in-situ observations. Weather Bull., 73, s1-s18 (in Japanese).

Kuwano-Yoshida, A., and S. Minobe, 2017: Storm track response to SST fronts in the northwestern Pacific region in an AGCM. J. Climate, 30, 1081-1102.

Kwon, Y.-O., M. A. Alexander, N. A. Bond, C. Frankignoul, H. Nakamura, B. Qiu, and L. Thompson, 2010: Role of the Gulf Stream and Kuroshio-Oyashio system in large-scale atmosphere-ocean interaction: A review. $J$. Climate, 23, 3249-3281.

Lazo, J. K., R. E. Morss, and J. L. Demouth, 2009: 300 Billion served: Sources, perceptions, used and values of weather forecasts. Bull. Amer. Meteor. Soc., 90, 785-798.

Lea, D., I. Mirouze, M. J. Martin, R. R. King, A. Hines, D. Walters, and M. Thurlow, 2015: Assessing a new coupled data assimilation system based on the Met Office coupled atmosphere, land, ocean, sea ice model. Mon. Wea. Rev., 143, 4678-4694.

Lebeaupin Brossier, C., P. Drobinski, K. Beranger, S. Bastin, and F. Orain, 2013: Ocean memory effect on the dynamics of coastal heavy precipitation preceded by a mistral event in the northwestern Mediterranean. Quart. J. Roy. Meteor., 139, 1583-1597.

Lien, G.-Y., T. Miyoshi, S. Nishizawa, R. Yoshida, H. Yashiro, S. A. Adachi, T. Yamaura, and H. Tomita, 2017: The near-real-time SCALE-LETKF system: A case of the September 2015 Kanto-Tohoku heavy rainfall. SOLA, 13, 1-6.

Liu, Z., S. Wu, S. Zhang, Y. Liu, and X. Rong, 2013: Ensemble data assimilation in a simple coupled climate model: The role of ocean-atmosphere interaction. $A d v$. Atmos. Sci., 30, 1235-1248.

Makihara, Y., 1996: A method for improving radar estimates of precipitation by comparing data from radars and raingauges. J. Meteor. Soc. Japan, 74, 459-480.

Manda, A., H. Nakamura, N. Asano, S. Iizuka, T. Miyama, Q. Moteki, M. K. Yoshioka, K. Nishi, and T. Miyasaka, 2014: Impacts of a warming marginal sea on torrential rainfall organized under the Asian summer monsoon.
Sci. Rep., 4, 5741, doi:10.1038/srep05741.

Miyoshi, T., and M. Kunii, 2012: The local ensemble transform Kalman filter with the Weather Research and Forecasting model: Experiments with real observations. Pure Appl. Geophys., 169, 321-333.

Peters, J. M., and R. S. Schumacher, 2015a: Mechanisms for organization and echo training in a flash-flood-producing mesoscale convective system. Mon. Wea. Rev, 143, 1058-1085.

Peters, J. M., and R. S. Schumacher, 2015b: The simulated structure and evolution of a quasi-idealized warmseason convective system with a training convective line. J. Atmos. Sci., 72, 1987-2010.

Peters, J. M., E. R. Nielsen, M. D. Parker, S. M. Hitchcock, and R. D. Schumacher, 2017: The impact of low-level moisture errors on model forecasts of an MCS observed during PECAN. Mon. Wea. Rev., 145, 35993624.

Price, J. F., 1981: Upper ocean response to a hurricane. J. Phys. Oceanogr., 11, 153-175.

Ruf, C. S., R. Atlas, P. S. Chang, M. P. Clarizia, J. L. Garrison, S. Gleason, S. J. Katzberg, Z. Jelenak, J. T. Johnson, S. J. Majumdar, A. O‘brian, D. J. Posselt, A. J. Ridley, R. J. Rose, and V. U. Zavorotny, 2016: New ocean winds satellite mission to probe hurricanes and tropical convection. Bull. Amer. Meteor. Soc., 97, 385-395.

Sasaki, Y. N., S. Minobe, T. Asai, and M. Inatsu, 2012: Influence of the Kuroshio in the East Chine Sea on the early summer (baiu) rain. J. Climate, 25, 6627-6645.

Sato, K., A. Manda, Q. Moteki, K. K. Komatsu, K. Ogata, H. Nishikawa, M. Oshika, Y. Otomi, S. Kunoki, H. Kanehara, T. Aoshima, K. Shimizu, J. Uchida, M. Shimoda, M. Yagi, S. Minobe, and Y. Tachibana, 2016: Influence of the Kuroshio on mesoscale convective systems in the baiu frontal zone over the East China Sea. Mon. Wea. Rev., 144, 1017-1033.

Schumacher, R. S., 2015: Sensitivity of precipitation accumulation in elevated convective systems to small changes in low-level moisture. J. Atmos. Sci., 72, 2507-2524.

Schumacher, R. S., and J. M. Peters, 2017: Near-surface thermodynamic sensitivities in simulated extremerain-producing mesoscale convective systems. Mon. Wea. Rev., 145, 2177-2200.

Sluka, T. C., S. G. Penny, E. Kalnay, and T. Miyoshi, 2016: Assimilating atmospheric observations into the ocean using strongly coupled ensemble data assimilation. Geophys. Res. Lett., 43, 752-759.

Small, R. J., S. P. deSzoeke, S.-P. Xie, L. O’Neil, H. Seo, Q. Song, P. Cornillon, M. Spall, and S. Minobe, 2008: Air-sea interaction over ocean fronts and eddies. Dyn. Atmos. Oceans, 45, 274-319.

Smith, P. J., A. M. Fowler, and A. S. Lawless, 2015: Exploring strategies for coupled 4D-Var data assimilation using an idealized atmosphere-ocean model. Tellus, 
67, 27025, doi:10.3402/tellusa.v67.27025

Smith, P. J., A. S. Lawless, and N. K. Nichols, 2017: Estimating forecast error covariances for strongly coupled atmosphere-ocean 4D-Var data assimilation. Mon. Wea. Rev., 145, 4011-4035.

Tomita, H., Y. Kawai, M. F. Cronin, T. Hihara, and M. Kubota, 2015: Validation of AMSR2 sea surface wind and temperature over the Kuroshio Extension Region. SOLA, 11, 43-47.

Tsuguti, H., and T. Kato, 2014a: Contributing factors of the heavy rainfall event at Amami-Oshima Island, Japan, on 20 October 2010. J. Meteor. Soc. Japan, 92, 163-183.

Tsuguti, H., and T. Kato, 2014b: Objective extraction of heavy rainfall events and statistical analysis on their characteristic features. Tenki, 61, 455-469 (in Japanese).

Usui, N., S. Ishizaki, Y. Fujii, H. Tsujino, T. Yasuda, and M. Kamachi, 2006: Meteorological research institute multivariate ocean variational estimation (move) system: Some early results. Adv. Space Res., 37, 806822.

Usui, N., T. Wakamatsu, Y. Tanaka, N. Hirose, T. Toyoda, S. Nishikawa, Y. Fujii, Y. Takatsuki, H. Igarashi, H. Nishikawa, Y. Ishikawa, T. Kuragano, and M. Kamachi, 2017: Four-dimensional variational ocean reanalysis: A 30-year high-resolution dataset in the western North Pacific (FORA-WNP30). J. Oceanogr., 73, 205-233.

Wada, A., 2009: Idealized numerical experiments associated with the intensity and rapid intensification of stationary tropical-cyclone-like vortex and its relation to initial sea-surface temperature and vortex-induced sea-surface cooling. J. Geophys. Res., 114, D18111, doi:10.1029/2009JD011993.

Wada, A., and M. Kunii, 2017: The role of ocean-atmosphere interaction in Typhoon Sinlaku (2008) using a regional coupled data assimilation system. J. Geophys. Res., 122, 3675-3695.

Wada, A., N. Kohno, and Y. Kawai, 2010: Impact of wave- ocean interaction on Typhoon Hai-Tang in 2005. SOLA, 6A, 13-16.

Wada, A., M. F. Cronin, A. J. Sutton, Y. Kawai, and M. Ishii, 2013: Numerical simulations of oceanic $p \mathrm{CO}_{2}$ variations and interactions between Typhoon Choiwan (0914) and the ocean. J. Geophys. Res., 118, 2667-2684.

Wada, A., T. Uehara, and S. Ishizaki, 2014: Typhooninduced sea surface cooling during the 2011 and 2012 typhoon seasons: Observational evidence and numerical investigations of the sea surface cooling effect using typhoon simulations. Prog. Earth Planet. Sci., 1, 11, doi:10.1186/2197-4284-1-11.

Wada, A., M. Kunii, Y. Yonehara, and K. Sato, 2017: Impacts on local heavy rainfalls of surface winds measurement by seabirds soaring over the ocean during Typhoons Kilo and Etau (2015). WGNE Blue Book, Res. Activ. Atmos. Oceanic Model., 47, 1.27-1.28.

Whitaker, J. S., and T. M. Hamill, 2012: Evaluating methods to account for system errors in ensemble data assimilation. Mon. Wea. Rev., 140, 3078-3089.

Wu, L., B. Wang, and S. A. Braun, 2005: Impacts of airsea interaction on tropical cyclone track and intensity. Mon. Wea. Rev., 133, 3299-3314.

Xu, H., M. Xu, S.-P. Xie, and Y. Wang, 2011: Deep atmosphere response to the spring Kuroshio over the East China Sea. J. Climate, 24, 4959-4972.

Yonehara, Y., Y. Goto, K. Yoda, Y. Watanuki, L. C. Young, H. Weimerskirch, C.-A. Bost, and K. Sato, 2016: Flight paths of seabirds soaring over the ocean surface enable measurement of fine-scale wind speed and direction. PNAS, 113, 9039-9044.

Yoshida, K., and H. Itoh, 2012: Indirect effects of tropical cyclones on heavy rainfall events in Kyushu, Japan, during the Baiu season. J. Meteor. Soc. Japan, 90, 377-401.

Zhu, H., W. Ulrich, and R. K. Smith, 2004: Ocean effects on tropical cyclone intensification and inner-core asymmetries. J. Atmos. Sci., 61, 1245-1258. 